\title{
Topochemical deintercalation of Li from layered LiNiB: towards 2D MBene
}

Gourab Bhaskar, ${ }^{1}$ Volodymyr Gvozdetskyi, ${ }^{1}$ Maria Batuk, ${ }^{2}$ Kamila M. Wiaderek,${ }^{3}$ Yang Sun,${ }^{8}$ Renhai Wang, ${ }^{4,5}$ Chao Zhang, ${ }^{6}$ Scott L. Carnahan, ${ }^{1,4}$ Xun Wu, ${ }^{1,4}$ Raquel A. Ribeiro, ${ }^{7}$ Sergey L. Bud'ko, ${ }^{4,7}$ Paul C. Canfield, ${ }^{7}$ Wenyu Huang, ${ }^{1,4}$ Aaron J. Rossini, ${ }^{1,4}$ Cai-Zhuang Wang, ${ }^{4,7}$ KaiMing Ho, ${ }^{4,7}$ Joke Hadermann, ${ }^{2}$ Julia V. Zaikina ${ }^{1, *}$

${ }^{1}$ Department of Chemistry, Iowa State University, Ames, Iowa 50011, United States

${ }^{2}$ EMAT, Department of Physics, University of Antwerp, Antwerp 2020, Belgium

${ }^{3}$ Argonne National Laboratory, Lemont, Illinois 60439 United States

${ }^{4}$ Ames Laboratory, US DOE, Iowa State University, Ames, Iowa 50011, United States

${ }^{5}$ Department of Physics, University of Science and Technology of China, Hefei 230026, China

${ }^{6}$ Department of Physics, Yantai University, Yantai 264005, China

${ }^{7}$ Department of Physics and Astronomy, Iowa State University, Ames, Iowa 50011, United States

${ }^{8}$ Department of Applied Physics and Applied Mathematics, Columbia University, New York, NY 10027, United States

\section{Supporting Information}




\section{Table of Contents}

Content

Page no.

Experimental Details

S3-S6

Figure S1; Crystal structure of $R T$ - and HT-LiNiB

S6

Figures S2, S3; PXRD

S7

Figure S4; SEM

S8

Figure S5; PXRD

S9

Figures S6-S9; HAADF-STEM

S10-S14

Table S1; Total and Formation energies

S14

Figures S10, S11; Phonon spectra

S15

Figures S12-S14; PDF

S16-S18

Table S2; Refined parameters of $R T$-B

S19

Figure S15; PDF comparison- planar vs corrugated [NiB] layers in HT-B

S20

Figures S16, S17; Proposed schematics of evolution of layers

S21

Table S3; Refined parameters of $H T$-B

S22

Figure S18; PXRD

S22

Tables S4-S6; Inter- and intralayer bond distances, Bader charge analysis

S23

Figure S19; Field dependent magnetization

S24

Figure S20; Honda-Owen method

S25

Table S7; Fitting parameters

S26

References

S26-S27 


\section{Experimental.}

Synthesis of Precursors. Synthesis of both $R T$ - and HT-LiNiB compounds was reported in our recent work. ${ }^{\mathrm{S} 1}$ Briefly, lithium hydride, (AlfaAesar, 99.4\%) as a source of lithium, nickel powder (AlfaAesar, 99.996\%) and boron powder (AlfaAesar, amorphous \& crystalline, 98\%) were weighed in their respective optimized molar composition $(\mathrm{LiH}: \mathrm{Ni}: \mathrm{B}=1.3: 1: 1.15)$, ballmilled, sealed in tantalum tube and then was slowly heated $(1.25 \mathrm{~K} / \mathrm{min})$ from room temperature to $1173 \mathrm{~K}$. After annealing at $1173 \mathrm{~K}$ for $12 \mathrm{~h}$, tube was either allowed to cool to room temperature naturally by switching off the furnace ( $R T$-LiNiB), or was quenched in cold water (HT-LiNiB).

Topochemical deintercalation. Deintercalation of Li from both $R T$ - and $H T$-LiNiB phases was carried out in air, deionized water, ethanol and $10 \% \mathrm{~V} / \mathrm{V} \mathrm{HCl}$ at room temperature. For the reactions in deionized water and in $10 \% \mathrm{~V} / \mathrm{V} \mathrm{HCl}$, the precursors were placed into a two neck round bottom flask which was then attached to the Schlenk line under argon flow followed by injection of solvent in the flask. To minimize the presence of dissolved oxygen in the deionized water, argon gas was bubbled through the solvent. For the deintercalation of Li from $R T$ - and $H T$-LiNiB phases, dried, oxygen-free ethanol was added to the precursors inside an argon filled glovebox.

Powder X-ray Diffraction (PXRD). Rigaku MiniFlex600 powder diffractometer with $\mathrm{Cu}$ $K \alpha$ radiation $(\lambda=1.54051 \AA)$ and $\mathrm{Ni}-K_{\beta}$ filter was utilized to inspect the purity of the polycrystalline samples. Data collection was done in both air-sensitive and zero-background plate holders (in open air) at room temperature. Analysis of the phases was performed by using program PDXL. ${ }^{2}$ incorporated with PDF-2 database. To study mechanism of gradual Lideintercalation, PXRD patterns were collected at specific time intervals ranging from 20 minutes to one month.

Scanning transmission electron microscopy. High angle annular scanning transmission electron microscopy (HAADF STEM) images and electron energy-loss spectroscopy (STEMEELS) elemental maps were obtained with a probe aberration-corrected FEI Titan 80-300 "cubed" microscope operated at $300 \mathrm{kV}$. The data were recorded using a probe with a convergence semi-angle of $21 \mathrm{mrad}$ (probe size of $1 \AA$ ) and the probe current of about $45 \mathrm{pA}$. Acquisitions were done in the spectrum imaging mode (SI) so that the electron probes were scanned over the samples and in each point, an EELS spectrum was acquired together with a HAADF signal as an image reference. The individual elemental distribution maps were 
generated by placing an integration window over the background-subtracted absorption edges of the elements (Li K (55 eV); Ni L2,3 (855 eV); B K (188 eV); O K (532 eV); C K (284 eV); the $\mathrm{Ni}-\mathrm{M}_{2,3}$ line is at $68 \mathrm{eV}$ and therefore gives a low signal at Li maps).

Elemental Analysis. For the elemental analysis of the samples, a FEI Quanta-250 field emission scanning electron microscope (SEM) accoutered with Oxford X-Max 80 detector and an Oxford Aztec energy-dispersive X-ray spectroscopy (EDXS) analysis system were used. Holders with double-sided carbon tape, on which the powders were sprinkled to allow random arrangement of particles, were used for the measurements. The holders were oriented with a flat face perpendicular to the beam and analyzed using a $15 \mathrm{kV}$ accelerating voltage with an accumulation time exceeding 60s. No signals for the Ta (material of the container used for synthesis) or any other heavy elements besides Ni were detected, while B and Li contents are beyond the sensitivity limit of the EDXS method.

Inductively coupled plasma mass spectrometry (ICP-MS). ICP-MS measurements were carried out using a Thermo Fisher Scientific X Series 2 ICPMS. $50 \mathrm{mg}$ of powdered Lideintercalated samples of both $R T$ - and $H T$-LiNiB phases were digested in concentrated $\mathrm{HNO}_{3}$ (trace-metals grade) followed by dilution with deionized water to prepare $50 \mathrm{~mL}$ solution with the $\sim 2 \%$ concentration in respect to $\mathrm{HNO}_{3}$. Thereafter solutions with $\sim 100 \mathrm{ppb}$ concentration with respect to lithium and nickel have been prepared. $\mathrm{Li}$ and $\mathrm{Ni}$ content were determined by comparison of analytical signal of the sample with calibration curve based on their standard solutions with $0,10,25,50,100,150,200 \mathrm{ppb}$ ion concentration.

Solid-state NMR Spectroscopy. Solid-state ${ }^{7} \mathrm{Li}$ and ${ }^{11} \mathrm{~B}$ NMR spectra were measured on a Bruker Avance III HD spectrometer on a widebore $9.4 \mathrm{~T}\left(v_{1 \mathrm{H}}=400 \mathrm{MHz}\right) \mathrm{NMR}$ magnet. All spectra were collected in double mode on a Bruker $2.5 \mathrm{~mm} \mathrm{H-X-Y} \mathrm{triple} \mathrm{resonance} \mathrm{MAS} \mathrm{probe,}$ with ${ }^{7} \mathrm{Li}$ needing an additional capacitor to reach the proper frequency. Central transition selective pulses were used for ${ }^{7} \mathrm{Li}(11 \mu \mathrm{s} \pi / 2)$ while hard pulses were used for ${ }^{11} \mathrm{~B}(2.8 \mu \mathrm{s} \pi / 2)$. Pulses were optimized on a sample of oxidized LiNiB, and chosen to maximize intensity. The spin echoes were obtained with a rotor-synchronized sequence. $T_{l}$ was measured for all samples, and $1.3 \times T_{1}$ was used for ${ }^{7} \mathrm{Li}$, while $5 \times T_{1}$ was used for ${ }^{11} \mathrm{~B}$. Samples were packed in an air-free atmosphere and diluted by approximately 50 weight $\%$ in powdered poly(tetrafluoroethylene) to minimize conductivity effects under MAS. The MAS rate was $25 \mathrm{kHz}$ in all cases unless otherwise indicated. 
Synchrotron powder X-ray diffraction and X-ray Pair distribution function (PDF). High resolution synchrotron powder diffraction data for $R T$ - $\mathrm{LiNiB}$ and its Li-deintercalated product were collected at beamline 11-BM Advanced Photon Source (APS), Argonne National Laboratory with $\lambda=0.412749 \AA$ at $295 \mathrm{~K}$. For the measurement, powdered forms of both samples were filled in $0.7 \mathrm{~mm}$ outer diameter thick-wall $(0.1 \mathrm{~mm})$ silica capillary followed by sealing under vacuum and mounting on to a sample holder. Total scattering data suitable for PDF analysis were collected at beamline 17-BM at Advanced Photon Source (APS), Argonne National Laboratory for phase pure $R T$ - $\mathrm{LiNiB}, H T$ - $\mathrm{LiNiB}$ and their $\mathrm{Li}$-deintercalated products. Powdered samples were filled in $0.7 \mathrm{~mm}$ outer diameter thick-wall $(0.1 \mathrm{~mm})$ silica capillary, sealed under vacuum, and mounted into a secondary shield capillary ( $0.9 \mathrm{~mm}$ inner diameter, 1.1 $\mathrm{mm}$ outer diameter). High energy X-rays $(\lambda=0.24156 \AA)$ were combined with a large amorphous silicon-based area detector (Perkin-Elmer) to collect data to high $\mathrm{Q}$-values $\left(\mathrm{Q}_{\max }=\right.$ $\left.22 \AA^{-1}\right) .{ }^{\mathrm{S}-\mathrm{S} 6}$ An empty capillary was used as blank for background calibration. The data were corrected for background and Fourier transformed to yield the PDF, G(r), within PDFgetX3 ${ }^{S 7}$ Structural models were refined against the PDF data within PDFgui. ${ }^{\mathrm{S} 8}$

Magnetic Properties. Magnetic property measurements were done on the polycrystalline samples (mass $\sim 50-60 \mathrm{mg}$ ) packed in a gelatin capsule which was fixed inside a plastic straw. The data collection was done by using a Quantum Design MPMS XL and MPMS3 SQUID magnetometers. DC magnetic susceptibility measurements were carried out in an applied field of $50 \mathrm{Oe}, 1000 \mathrm{Oe}$, and $2000 \mathrm{Oe}$, in the 2-280 K range. Field-dependent measurements were carried out at $2 \mathrm{~K}, 100 \mathrm{~K}, 200 \mathrm{~K}$, and $300 \mathrm{~K}$. Ac susceptibility measurements were performed using MPMS3 magnetometer with ac field amplitude of 5 Oe and zero bias dc field.

Computational methods. First-principles calculations were carried out using density functional theory (DFT) within a generalized gradient approximation (GGA) by VASP code. ${ }^{\text {S9- }}$ S11 The projector augmented-wave method ${ }^{\mathrm{S} 12}$ was used to describe the valence configuration: $1 s^{2} 2 s^{1}$ for $\mathrm{Li}, 3 d^{8} 4 s^{2}$ for $\mathrm{Ni}$, and $2 s^{2} 2 p^{1}$ for $\mathrm{B}$. The GGA exchange-correlation energy functional parameterized by Perdew, Burke, and Ernzerhof ${ }^{511}$ and a plane-wave basis with a kinetic energy cutoff of $650 \mathrm{eV}$ were utilized. Monkhorst-Pack's scheme ${ }^{\mathrm{S} 13}$ was adopted for Brillouin zone sampling with a $k$-point grid of $2 \pi \times 0.033 \AA^{-1}$, and the ionic relaxations were stopped when the forces on every atom became smaller than $0.01 \mathrm{eV} / \AA$. The calculations of phonon density of 
states were performed using the finite displacement with the supercell approach provided by the Phonopy code. ${ }^{\text {S14, S15 }}$

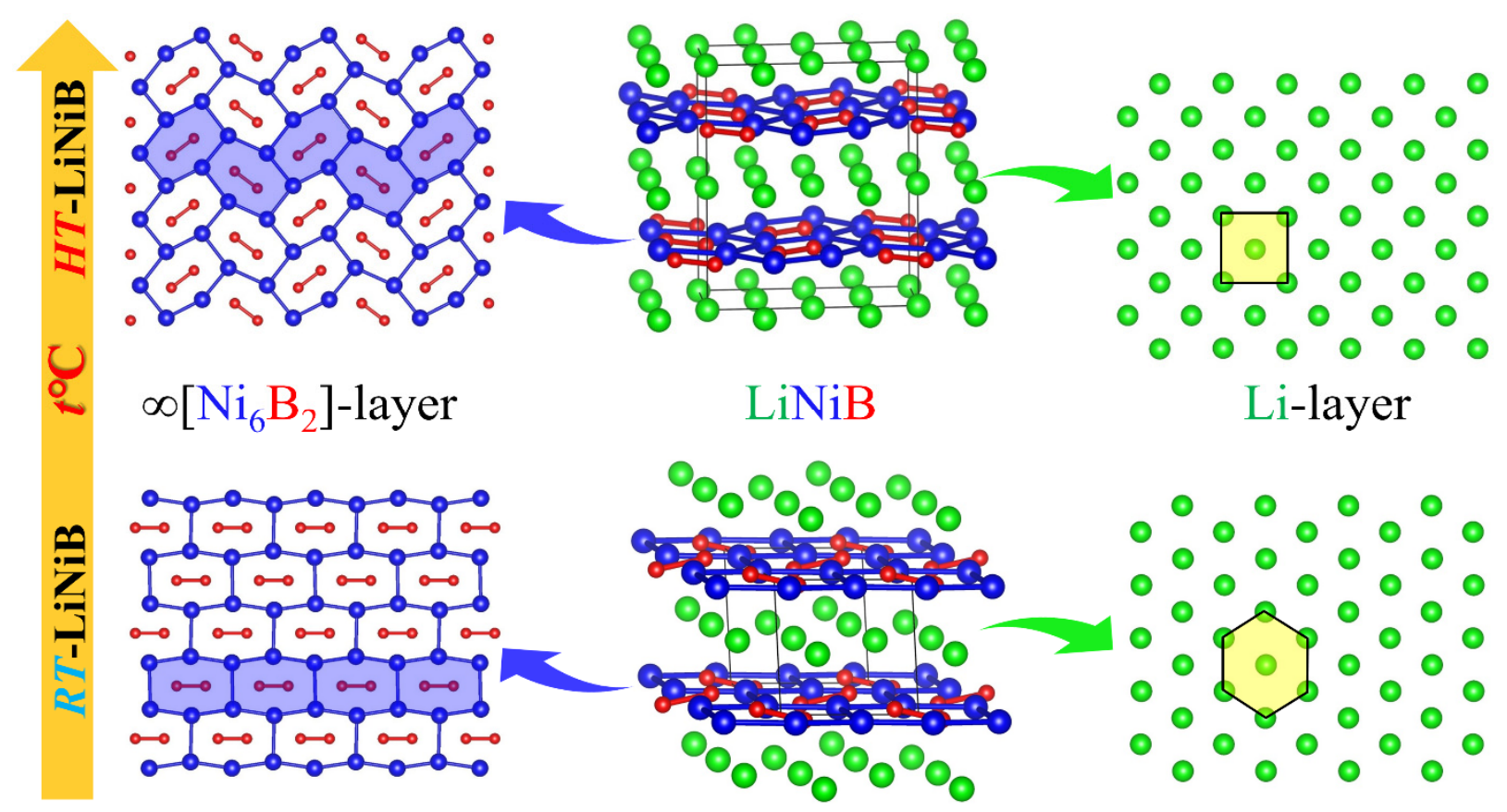

Figure S1. Crystal structure of $R T$-LiNiB and its high temperature sibling $H T$-LiNiB. 

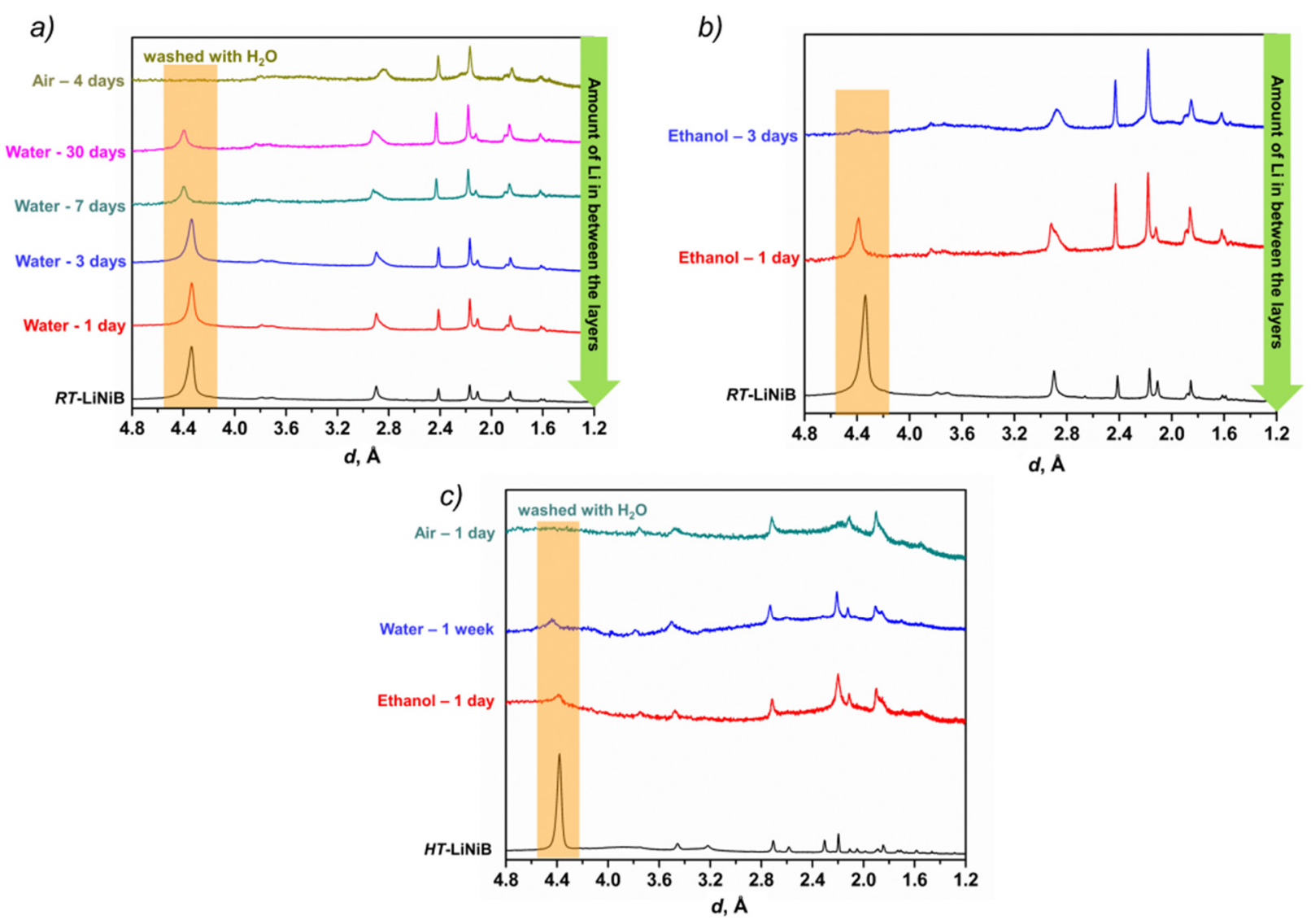

Figure S2. Powder X-ray diffraction (PXRD) pattern of $R T$-LiNiB exposed to water (a) and ethanol (b), and that of HT-LiNiB exposed to water and ethanol (c). PXRD pattern of air exposed sample is added for comparison.
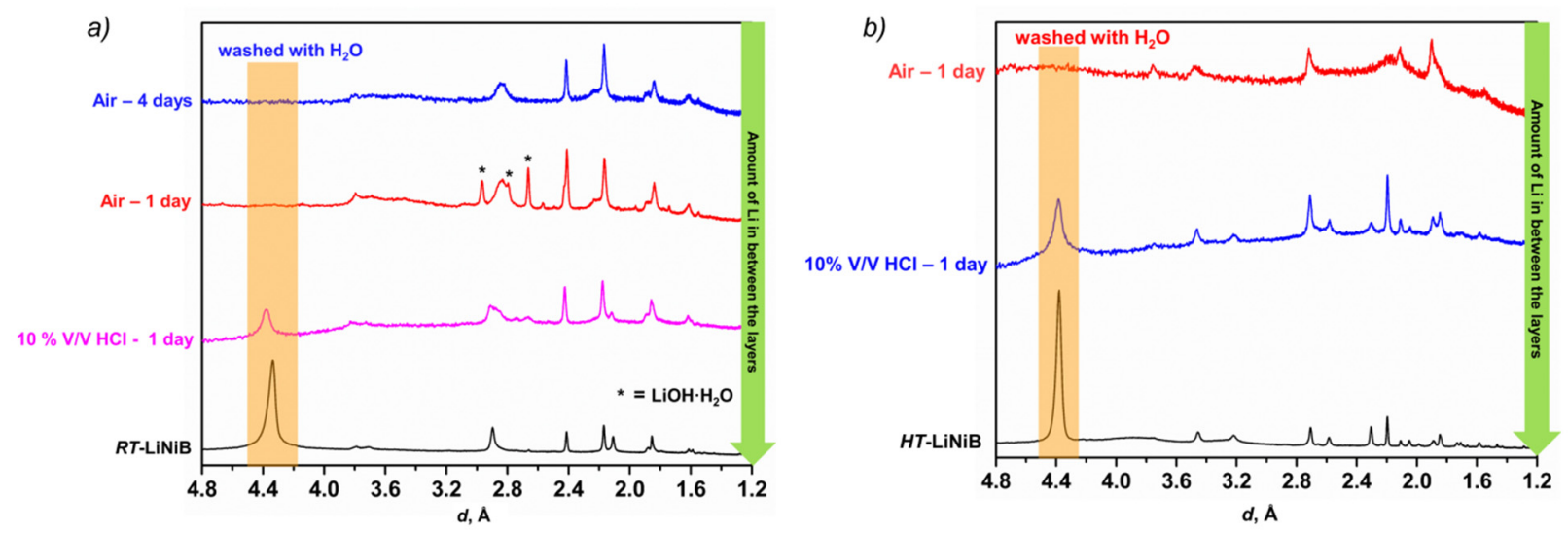

Figure S3. Powder X-ray diffraction (PXRD) pattern of $R T-\mathrm{LiNiB}$ (a) and $H T$-LiNiB (b) exposed to $10 \% \mathrm{~V} / \mathrm{V} \mathrm{HCl}$. PXRD pattern of air exposed sample is added for comparison. 

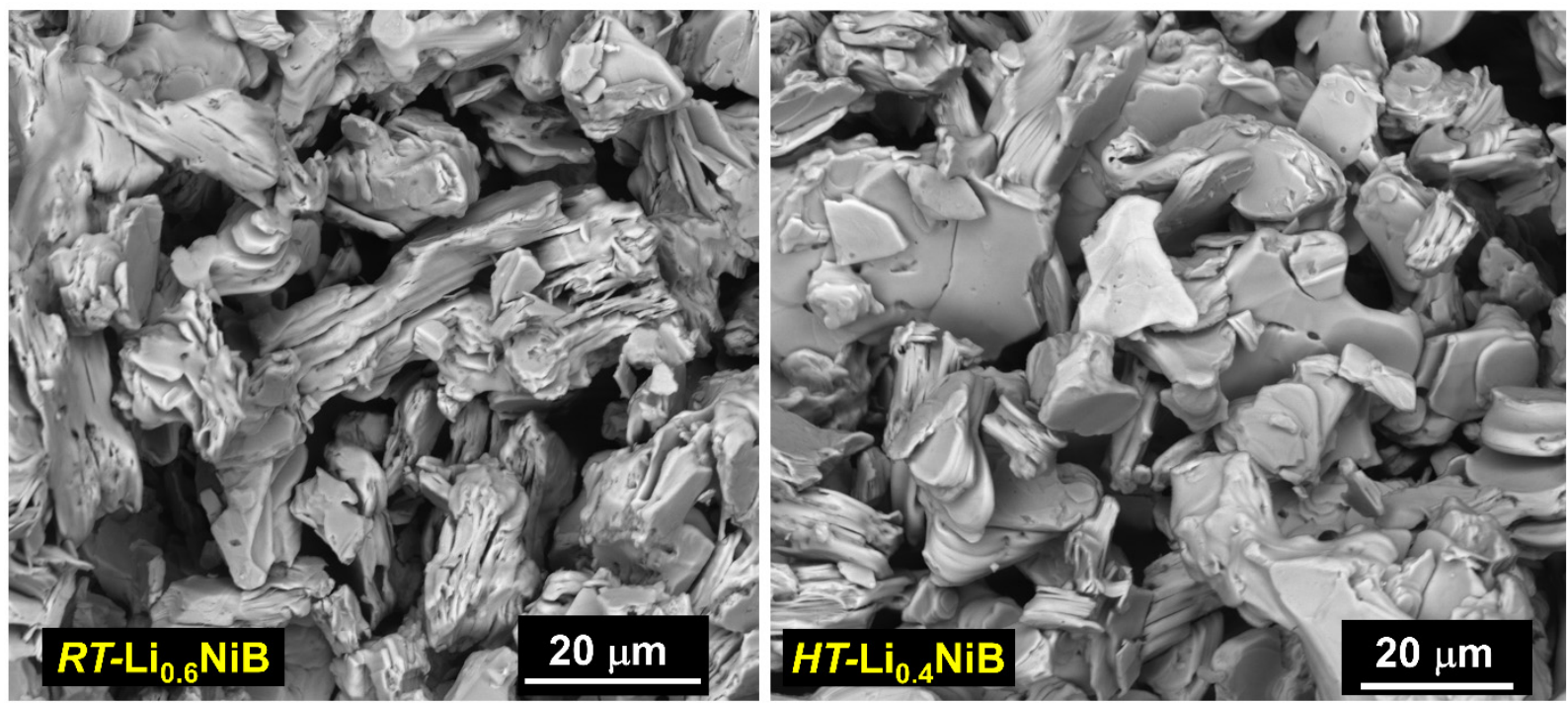

Figure S4. Backscattered Electron (BSE) images of $R T$-Li ${ }_{0.6} \mathrm{NiB}$ (left) and $H T-\mathrm{Li}_{0.4} \mathrm{NiB}$ (right) confirms layered morphology of these phases in bulk. 


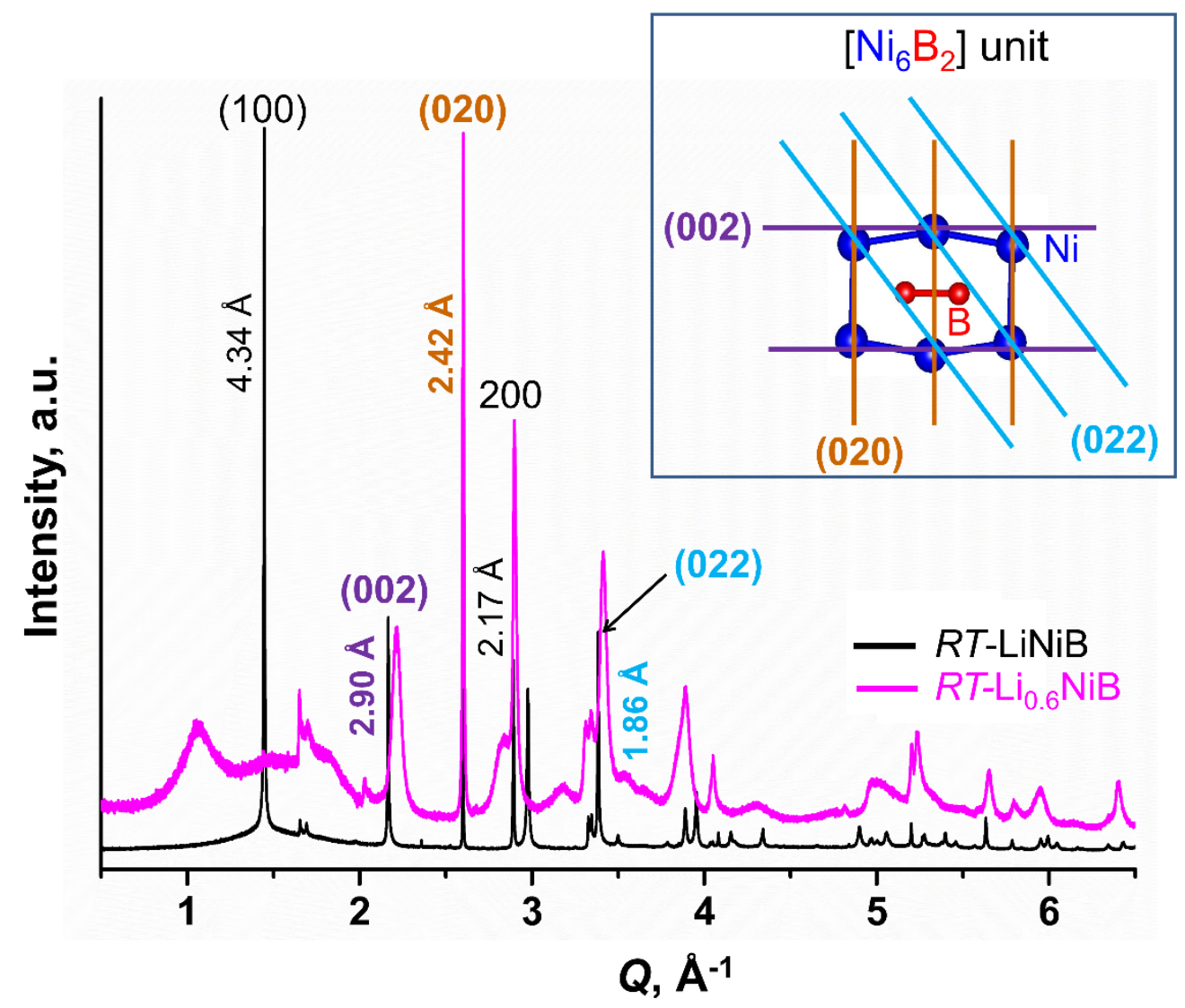

Figure S5. Comparison of $\mathrm{X}$-ray powder diffraction patterns of $R T$-LiNiB and its $\mathrm{Li}-$ deintercalated product, $R T$-Li . $_{6} \mathrm{NiB}$. Miller indices for the selected Bragg peaks in the structure of the parent $R T$-LiNiB $\left(R T(m)\right.$-LiNiB polytype, space group $P 2{ }_{1} / c, a=4.587 \AA, b=4.822 \AA, c=$ $6.153 \AA, \beta=109.71^{\circ}$ ) are emphasized.

The deintercalation of Li from $R T$-LiNiB cannot be understood by a simple decrease of interlayer distances. For instance, the Bragg peak (100), corresponding to the interlayer spacing between adjacent $[\mathrm{NiB}]$ layers in $R T$ - $\mathrm{LiNiB}\left(d_{100}=4.34 \AA\right)$ is absent in the deintercalated product. Bragg peak $(200)\left(d_{200}=2.17 \AA\right)$ corresponding to the distance between $[\mathrm{NiB}]$ and Li layers in $R T$ LiNiB is slightly shifted in $R T-\mathrm{Li} 0.6 \mathrm{NiB}$, since this becomes a distance between two [NiB] layers within $[\mathrm{NiB}]_{2}$ fragment in accordance with STEM images. Bragg peaks (002), (020) and (022) are preserved and only slightly shifted after deintercalation indicating that dimensions of the basic $\mathrm{Ni}_{6} \mathrm{~B}_{2}$ units composing the $[\mathrm{NiB}]$ layer do not change significantly. 


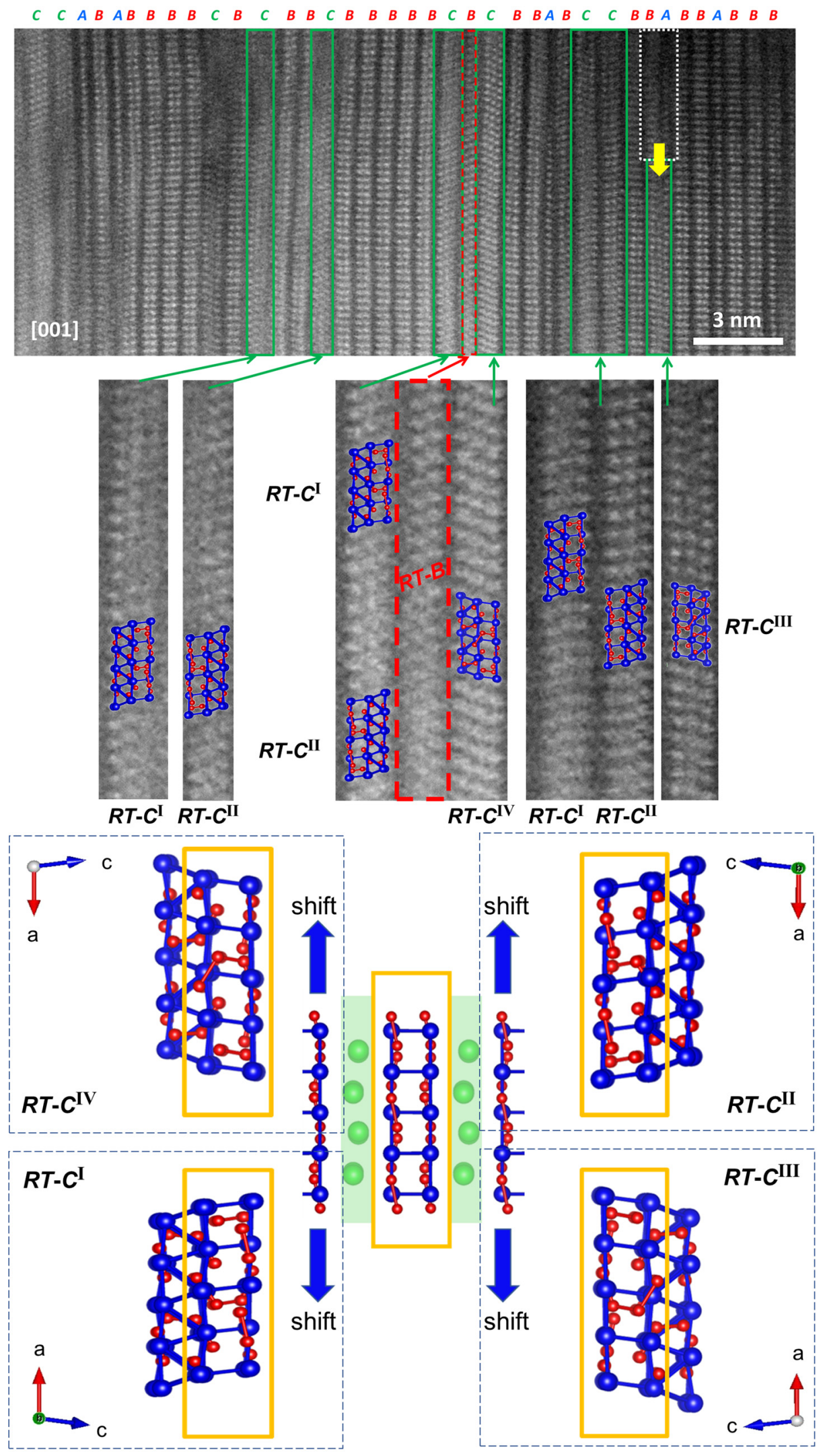


Figure S6. HAADF-STEM image of $R T-\mathrm{Li}_{0.6} \mathrm{NiB}$ with $R T-\mathrm{C}\left(\mathrm{Li}[\mathrm{NiB}]_{3}\right)$ substructure shown in green rectangles. The viewing zone axis is [001] with respect to the parent structure. In these images the bright dots correspond to the columns of $\mathrm{Ni}$ atoms, however columns of $\mathrm{Li}$ and $\mathrm{B}$ atoms cannot be seen so we assumed the absence of contrast between the Ni columns is equivalent to Li layers. The four different orientations $\left(R T-C^{\mathrm{I}}, R T-C^{\mathrm{II}}, R T-C^{\mathrm{III}}\right.$, and $\left.R T-C^{\mathrm{IV}}\right)$ of the $R T-\mathrm{C}\left(\mathrm{Li}[\mathrm{NiB}]_{3}\right)$ substructure are randomly distributed since the deintercalation of Li layers occurs randomly. After the first Li layer is removed, depending on which of the other nearest $\mathrm{Li}$ layers is removed next, four different scenarios can occur (bottom), leading to $R T-C^{\mathrm{I}}, R T-C^{\mathrm{II}}, R T$ $C^{\mathrm{III}}$, and $R T-C^{\mathrm{IV}}$ orientations. Noticeably, while removing one Li layer does not cause a shift between the condensed two $[\mathrm{NiB}]$ layers in the $R T$-B substructure, removing the second adjacent Li layer entails a shift of the third [NiB] layer. Such reorganization of the [NiB] layers affects the adjacent $[\mathrm{NiB}]$ layers of the neighboring substructures, causing a relative shift of [NiB] layers. For instance, a certain shift of $[\mathrm{NiB}]$ layers is observed in those $R T-B$ fragments surrounded by $R T$-C, as highlighted by a red dashed box. 

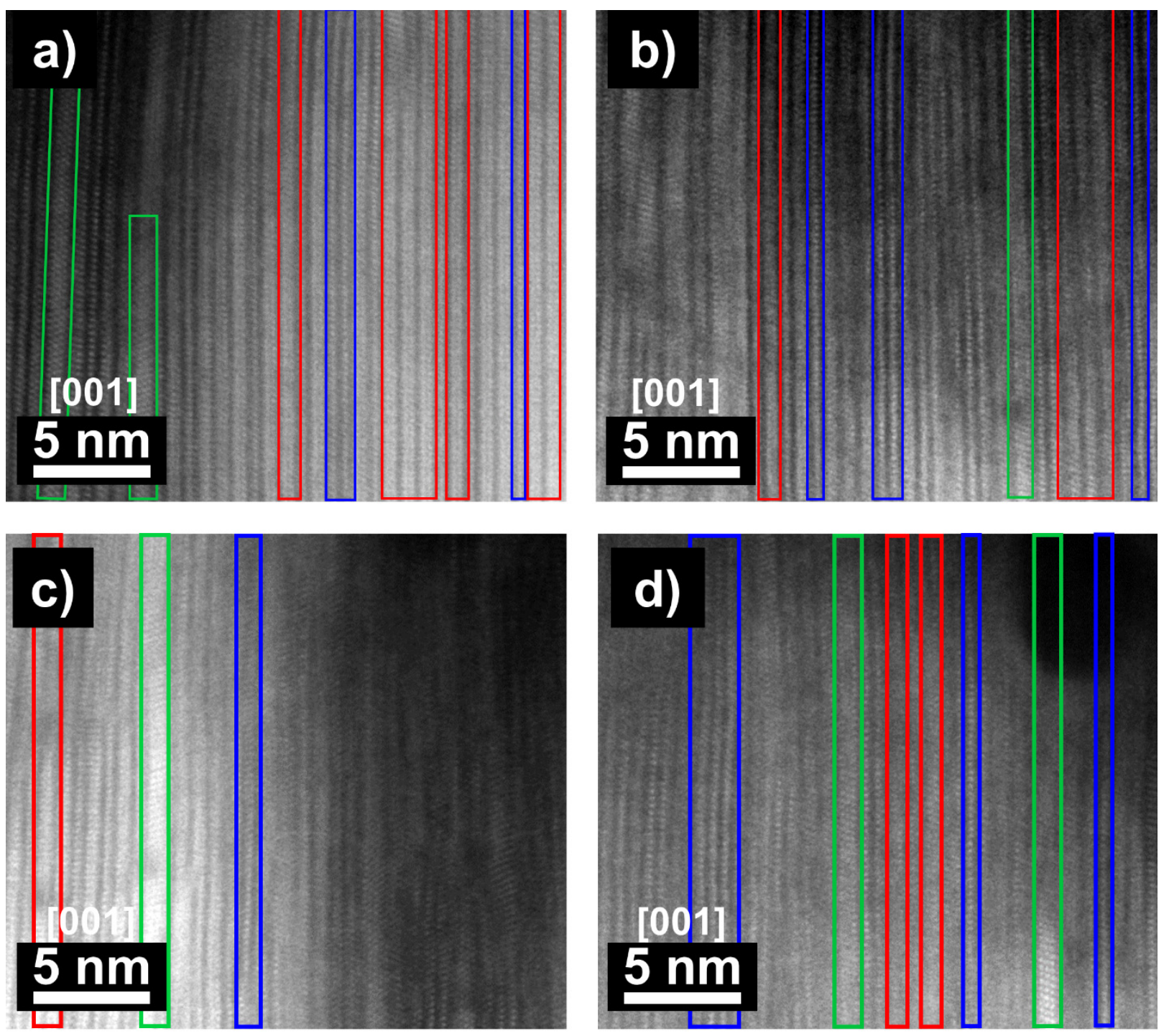

Figure S7. The HAADF-STEM images of $R T$-Li0.6 NiB demonstrate random distribution of 3 substructures: $R T-A(\mathrm{Li}[\mathrm{NiB}]), R T-B\left(\mathrm{Li}[\mathrm{NiB}]_{2}\right)$ and $R T-C\left(\mathrm{Li}[\mathrm{NiB}]_{3}\right)$ represented respectively in blue, red and green colored rectangles. Li:Ni ratio was found to be $0.59: 1,0.61: 1,0.62: 1$ and $0.66: 1$ for the images $a-d$ respectively. In these images the bright dots correspond to the columns of $\mathrm{Ni}$ atoms, however columns of $\mathrm{Li}$ and $\mathrm{B}$ atoms cannot be seen so we assumed that the absence of contrast between the Ni columns is equivalent to Li layers. 


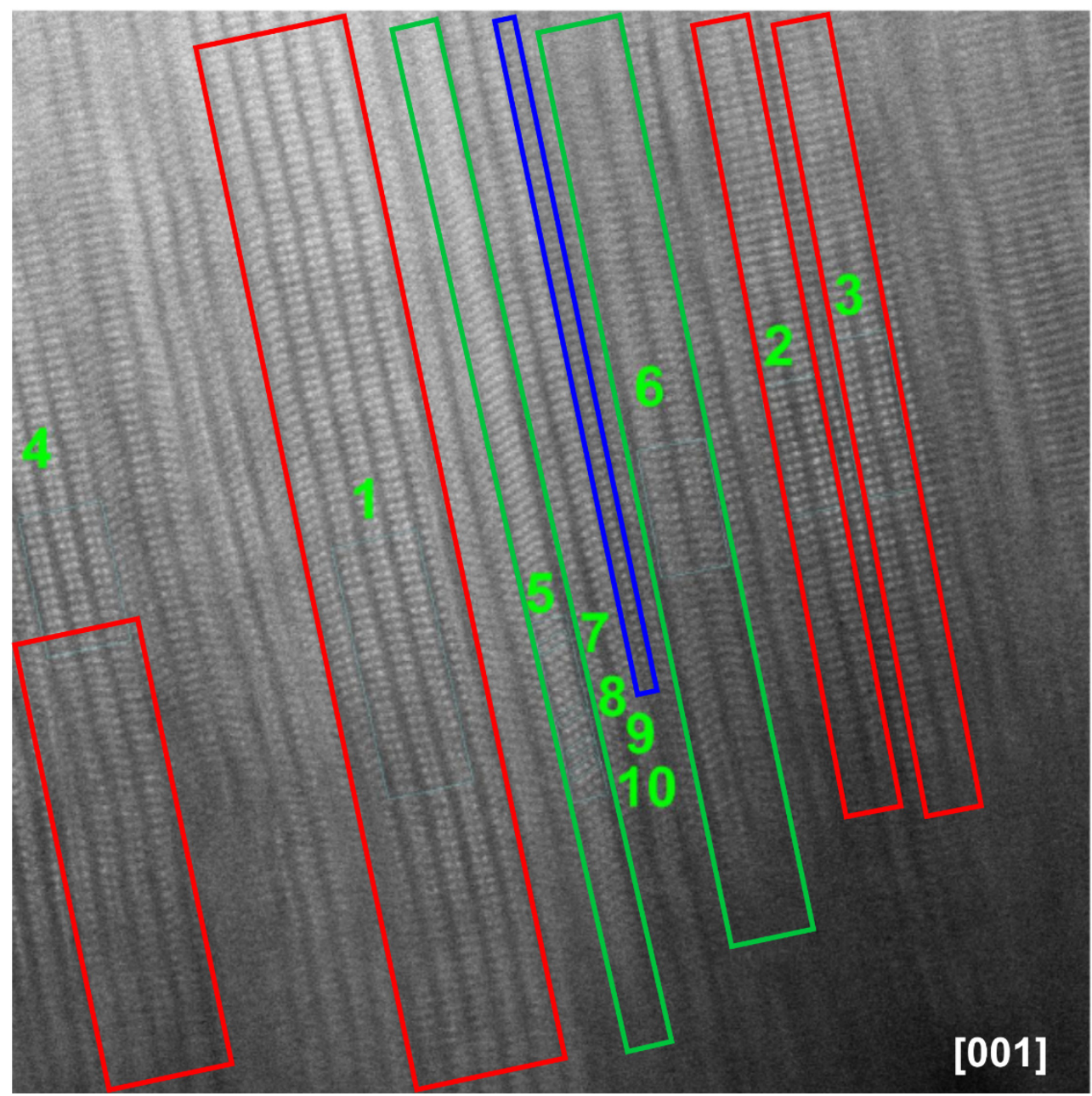

Figure S8. Interlayer distances between $[\mathrm{NiB}]$ layers in substructures $R T-B\left(\mathrm{Li}[\mathrm{NiB}]_{2}\right)$ and $R T-C$ $\left(\mathrm{Li}[\mathrm{NiB}]_{3}\right)$ have been determined from HAADF-STEM image of $R T$-Li $0.6 \mathrm{NiB}$. Here, areas 1-4 correspond to substructure $R T-B$ and areas 5-6 correspond to substructure $R T-C$. Individual rows 7-10 were also considered to measure distances. An average interlayer distance in the $R T-B$ substructures was found to be $2.2 \pm 0.1 \AA$, whereas that in substructure $R T-C$ was found to be $2.1 \pm 0.1 \AA$. Here $R T-A(\mathrm{Li}[\mathrm{NiB}]), R T-B\left(\mathrm{Li}[\mathrm{NiB}]_{2}\right)$ and $R T-C\left(\mathrm{Li}[\mathrm{NiB}]_{3}\right)$ represented respectively in blue, red and green colored rectangles. In these images the bright dots correspond to the columns of $\mathrm{Ni}$ atoms, however columns of $\mathrm{Li}$ and $\mathrm{B}$ atoms cannot be seen so we assumed the absence of contrast between the Ni columns is equivalent to Li layers. 

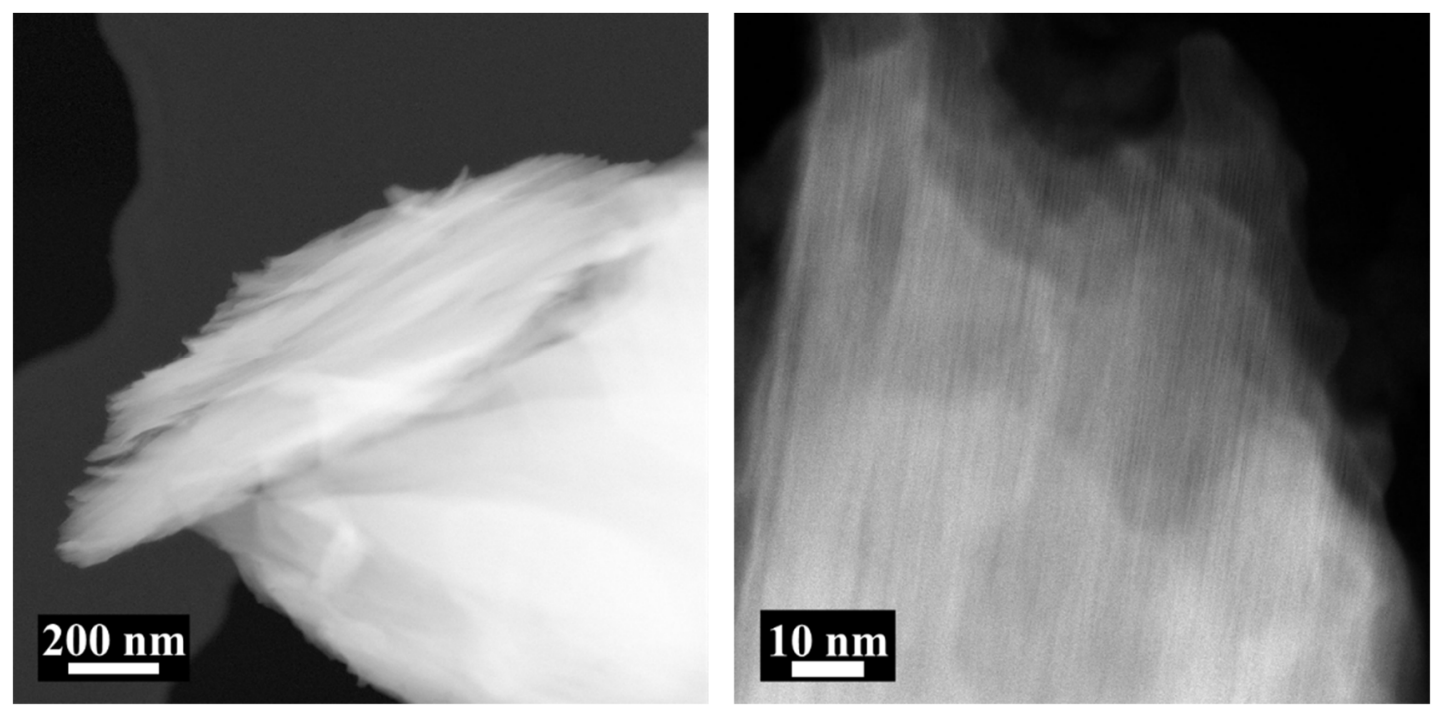

Figure S9. The HAADF-STEM images of $H T$ - $\mathrm{Li}_{0.4 \mathrm{NiB}} \mathrm{Nhow}$ poor crystallinity of the compound making acquirement of the atomic resolution snapshot, impossible. Still these images indicate a presence of non-uniform layered structure.

Table S1. Total energy $(E)$ and formation energy $\left(E_{f}\right)$ of different fragments of $R T$-Liv.6NiB and $H T$-Li $0.4 \mathrm{NiB}$.

\begin{tabular}{c|ccccc}
\hline Fragment & Li\# & $N i \#$ & $B \#$ & $E$, eV/atom & $E_{\mathrm{f}, \text { eV/atom }}$ \\
\hline$R T-\mathrm{LiNiB}$ & 4 & 4 & 4 & -5.030 & -0.338 \\
$R T-B\left(\mathrm{Li}[\mathrm{NiB}]_{2}\right)$ & 4 & 8 & 8 & -5.484 & -0.233 \\
$R T-B\left(\mathrm{Li}[\mathrm{NiB}]_{2}\right) \exp$ & 4 & 8 & 8 & -5.475 & -0.224 \\
$R T-C\left(\mathrm{Li}[\mathrm{NiB}]_{3}\right)$ & 4 & 12 & 12 & -5.703 & -0.214 \\
$R T-[\mathrm{NiB}]_{\infty}$ & 0 & 4 & 4 & -5.821 & 0.266 \\
$R T-\mathrm{NiB}(2 \mathrm{D})$ & 0 & 4 & 4 & -5.820 & 0.267 \\
$H T-\mathrm{LiNiB}$ & 8 & 8 & 8 & -5.000 & -0.310 \\
$H T-B\left(\mathrm{Li}[\mathrm{NiB}]_{2}\right)$ & 4 & 8 & 8 & -5.483 & -0.233 \\
$H T-B\left(\mathrm{Li} 0.75[\mathrm{NiB}]_{2}\right)$ & 3 & 8 & 8 & -5.567 & -0.141 \\
$H T-B\left(\mathrm{Li} 0.75[\mathrm{NiB}]_{2}\right) \exp$ & 3 & 8 & 8 & -5.564 & -0.137 \\
$H T-C\left(\mathrm{Li}[\mathrm{NiB}]_{3}\right)$ & 4 & 12 & 12 & -5.680 & -0.192 \\
$H T-[\mathrm{NiB}]_{\infty}$ & 0 & 8 & 8 & -5.831 & 0.255 \\
$H T-\mathrm{NiB}(2 \mathrm{D})$ & 0 & 4 & 4 & -5.829 & 0.257
\end{tabular}




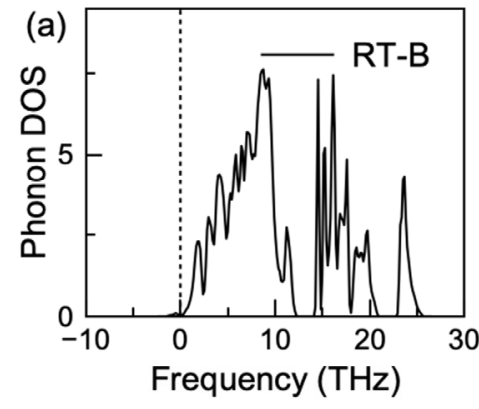

(d) RT-C, soft modes

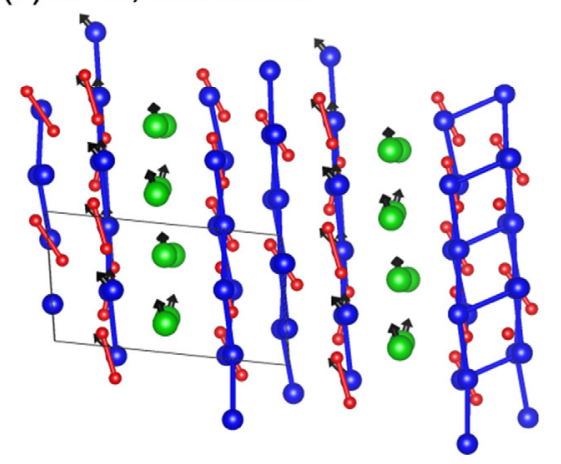

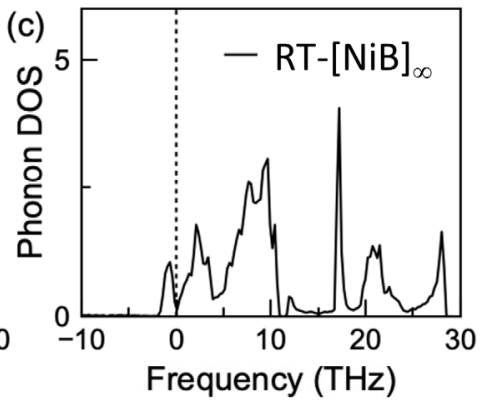

(e) RT-NiB, soft modes

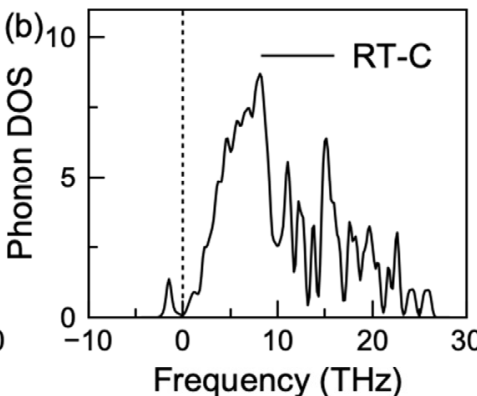

Figure S10. The phonon spectra of (a) $R T-B\left(\mathrm{Li}[\mathrm{NiB}]_{2}\right)$, (b) $R T-\mathrm{C}\left(\mathrm{Li}[\mathrm{NiB}]_{3}\right)$ and (c) $R T-[\mathrm{NiB}]_{\infty}$. The arrows indicate the atomic displacements of the negative phonon modes; (d), $R T$-C soft modes, (e) RT-NiB soft modes. Green, blue and red spheres are Li, Ni and B, respectively.
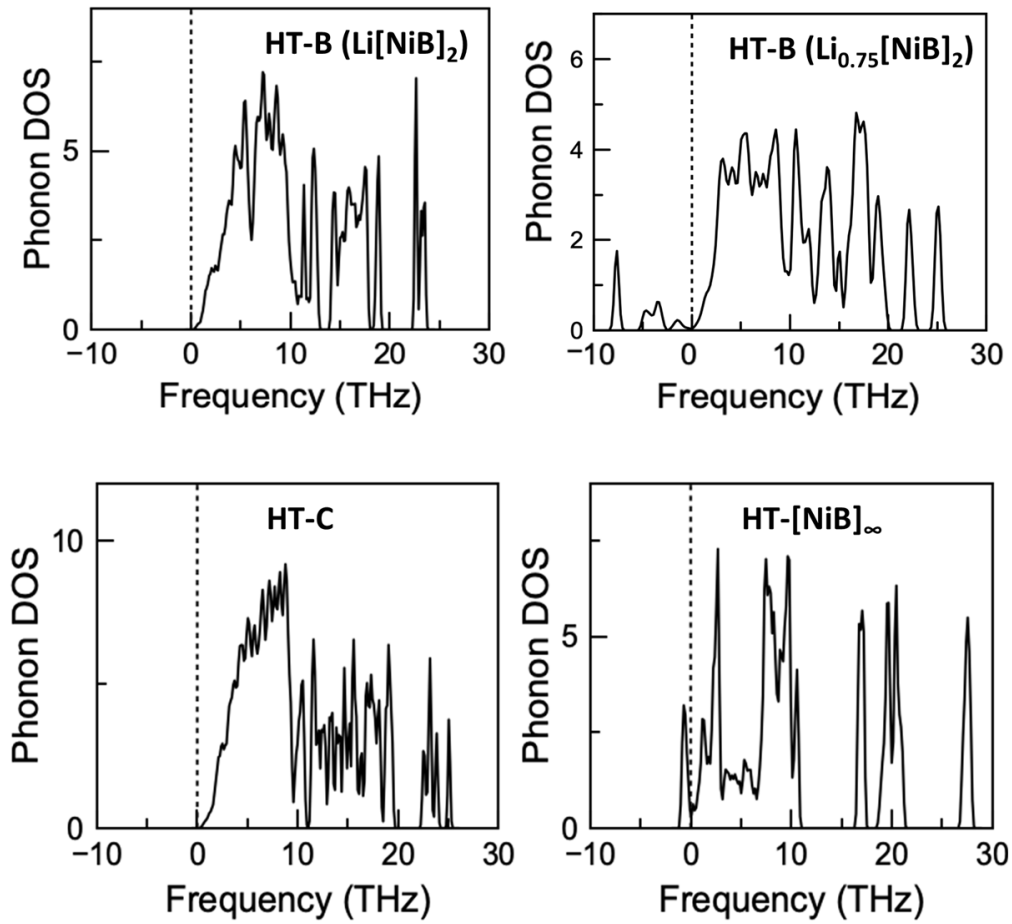

Figure S11. The phonon spectra of $H T-B\left(\mathrm{Li}[\mathrm{NiB}]_{2}\right), H T-B\left(\mathrm{Li}_{0.75}[\mathrm{NiB}]_{2}\right), H T-\mathrm{C}\left(\mathrm{Li}[\mathrm{NiB}]_{3}\right)$ and $H T-[\mathrm{NiB}]_{\infty}$. 


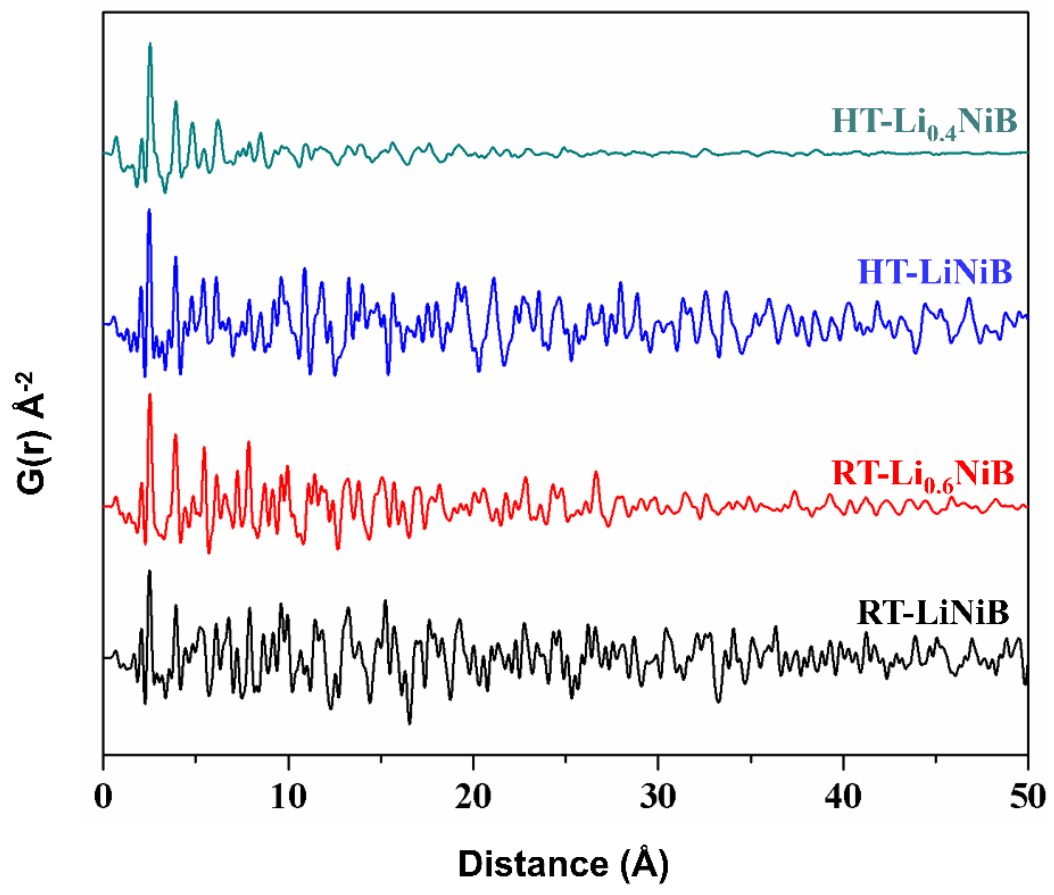

Figure S12. Pair distribution function of $R T$ - $\mathrm{LiNiB}, H T-\mathrm{LiNiB}$ and their Li-deintercalated products. $R T$-LiNiB and $H T$ - $\mathrm{LiNiB}$ compounds are highly crystalline materials with the long range order while $R T$-Lio.6 $\mathrm{NiB}$ and $H T$-Lio. $4 \mathrm{NiB}$ phases exhibit only short range order. 
a)

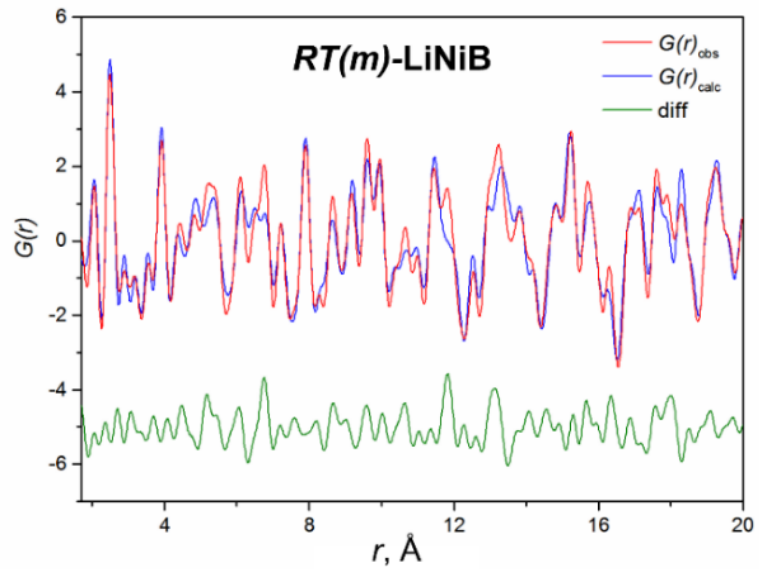

b)

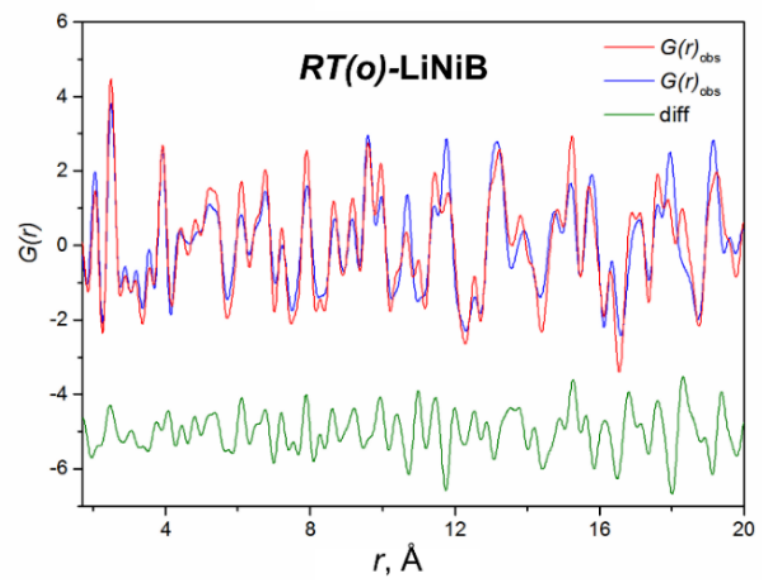

c)

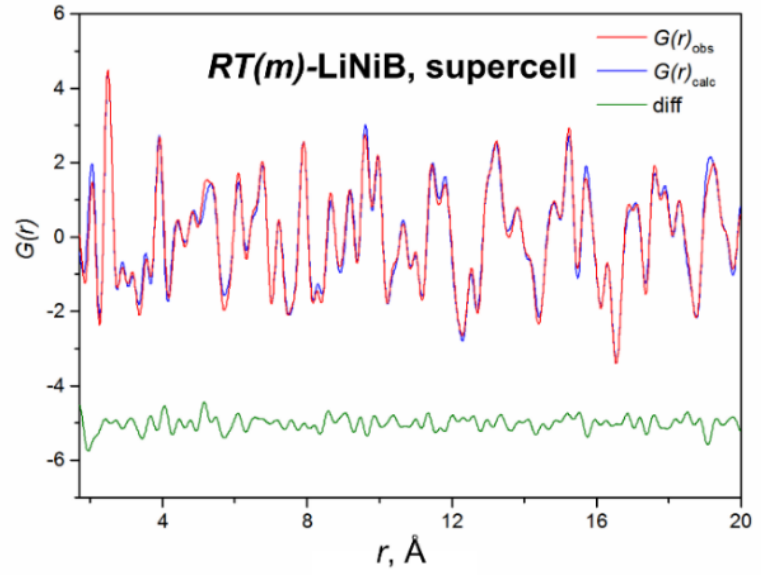

Figure S13. Fitting of the X-ray PDF data of $R T$-LiNiB compound with models $R T(m)$ LiNiB $\left(P 2{ }_{1} / c, \quad R=0.32\right), \quad R T(o)-\mathrm{LiNiB}$ $\left(C m c 2_{1}, R=0.41\right)$ and $R T(m)-\operatorname{LiNiB}\left(P 2_{1} / c\right.$, supercell $4 a \times b \times c, R=0.14)$.

As it was previously established, ${ }^{\mathrm{S} 1}$ the crystal structure of $R T$-LiNiB can be described either as an intergrowth of two polytypes (polytype 1: RT(m)-LiNiB, space group $P 2{ }_{1} / c, a=4.587 \AA, b=4.822 \AA, c=$ $\left.6.153 \AA, \beta=109.71^{\circ}\right)$; polytype 2: RT(o)LiNiB, space group $C m c 21, a=4.8177 \AA$, $b$ $=6.1421 \AA, c=8.641 \AA)$ ) or as a superstructure of the $R T(m)$-LiNiB polytype with the fourfold enlargement of the $a$ parameter $\left(P 2{ }_{1} / c, a_{\text {superstr }}=4 a=18.451, b\right.$ $\left.=4.8336, c=6.1573 \AA, \beta=109.636^{\circ}\right)$. The best fit of the X-ray PDF data was obtained for the superstructure $\left(P 2{ }_{1} / c\right.$, supercell $4 a \times b \times c, \quad R=0.14$ ), unambiguously indicating that this is the better approximation of the real structure for the $R T$-LiNiB compound with the complex intergrowth of [NiB] layers.

The X-ray PDF data fit with each of the two polytypes $R T(m)$-LiNiB $\left(P 2{ }_{1} / c, R=0.32\right)$ and $R T(o)$-LiNiB $\left(C m c 2_{1}, R=0.41\right.$ did not produce sufficiently good fit $(a-b)$. 

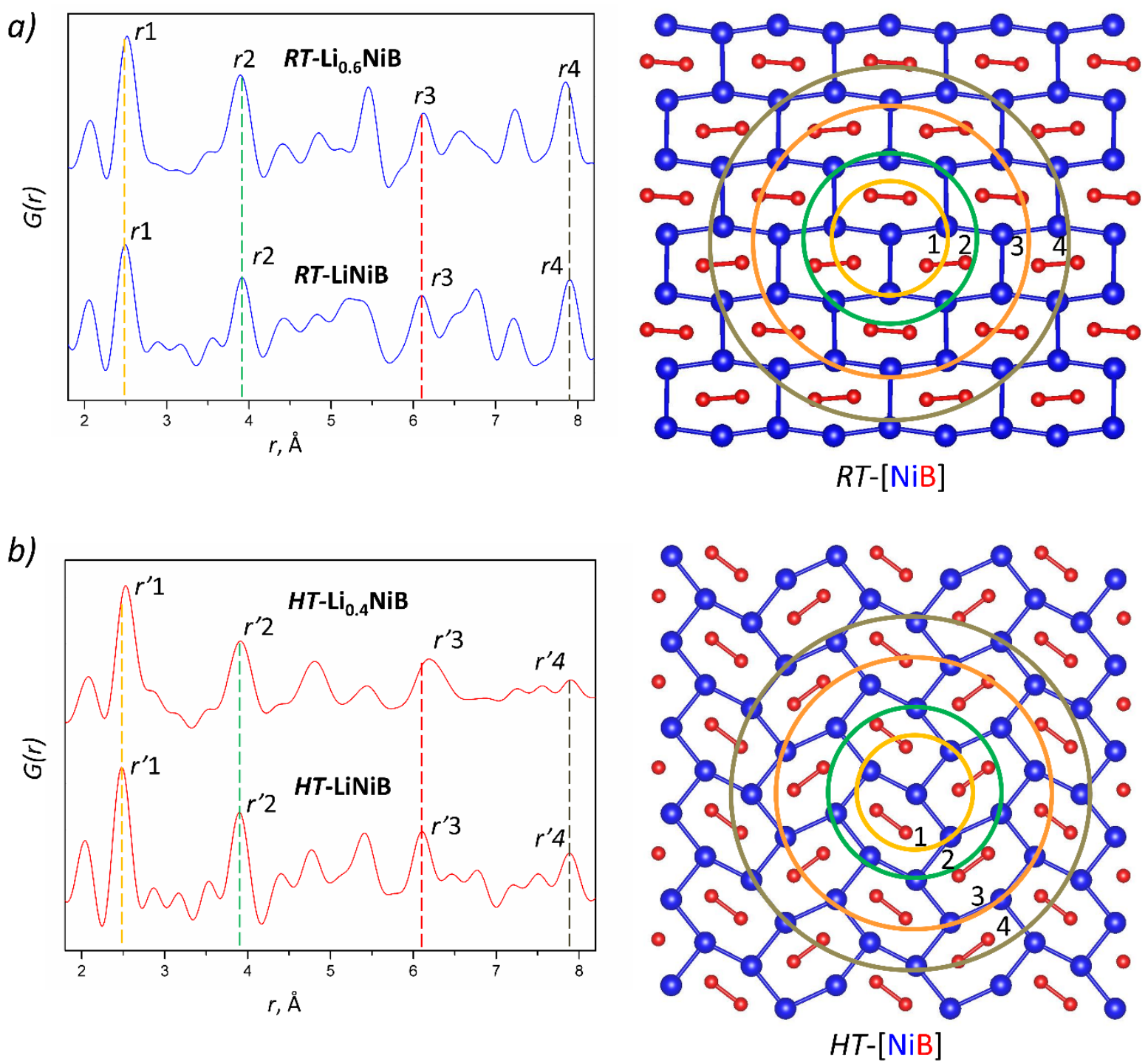

Figure S14. Comparison of PDF in 2-8 $\AA$ range of a) $R T$-LiNiB and $R T$-Li0.6 NiB, b) $H T$-LiNiB, and $H T$-Li $0.4 \mathrm{NiB}$. Slightly shifted peaks on $G(r)$ indicate presence of moderate distortion of the $[\mathrm{NiB}]$ layers. Selected distances between $\mathrm{Ni}$ atoms within layers are highlighted. 
Table S2. Atomic coordinates and isotropic equivalent displacement parameters of the $R T-B$ $\mathrm{Li}[\mathrm{NiB}]_{2}$ fragment. Refined parameters based on synchrotron powder X-ray PDF data at $295 \mathrm{~K}$ are listed.

\begin{tabular}{cccccc}
\hline Site & Wyckoff site & $x$ & $y$ & $z$ & $U_{\text {iso, }} \AA^{2}$ \\
\hline$R T-B$ Li[NiB $]_{2}(m P 20, P 21 / c, a=7.12(1)$, & $b=4.818(3), c=6.202(4) \AA, \beta=113.13(9)^{\circ}, Z=4$, \\
\multicolumn{6}{c}{$R=0.25)$} \\
Li1 & $4 e$ & 0.02339 & 0.23541 & 0.37519 & $0.010(4)$ \\
Ni1 & $4 e$ & $0.330(2)$ & $0.501(2)$ & $0.318(1)$ & $0.004(1)$ \\
Ni2 & $4 e$ & $0.318(2)$ & $0.010(2)$ & $0.220(1)$ & $0.004(1)$ \\
B1 & $4 e$ & 0.37494 & 0.31725 & 0.03921 & $0.010(4)$ \\
B2 & $4 e$ & 0.32206 & 0.67412 & 0.01388 & $0.010(4)$ \\
\hline
\end{tabular}



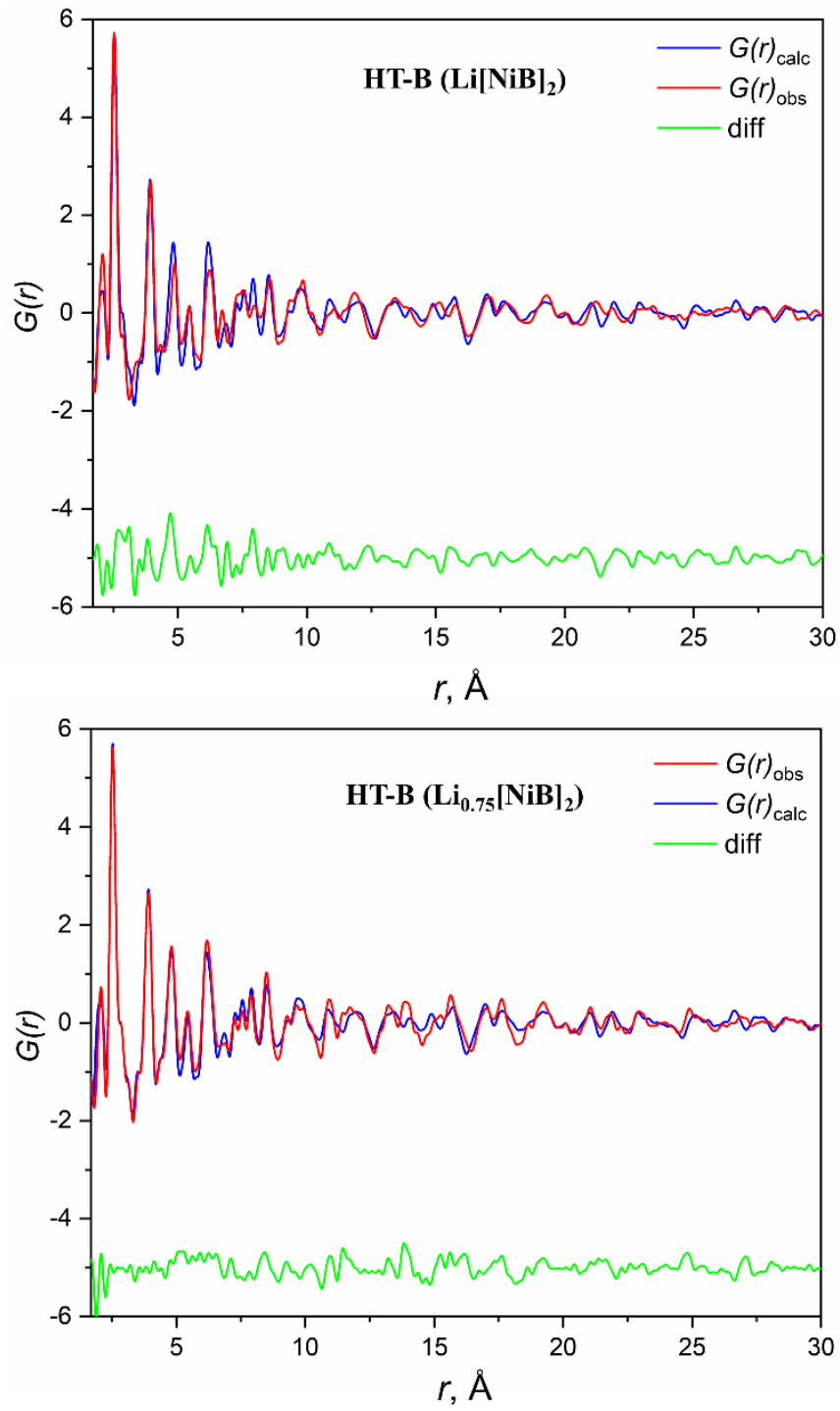

Figure S15. Fitting of the X-ray PDF data of $H T$ - $\mathrm{Li}_{0.4 \mathrm{NiB}}$ compound with planar (top) and corrugated (bottom) $[\mathrm{NiB}]$ layer in substructure $H T$-B, illustrate better fitting with the corrugated model $(R=0.27)$, than the planar one $(R=0.37)$. 
HT-LiNiB

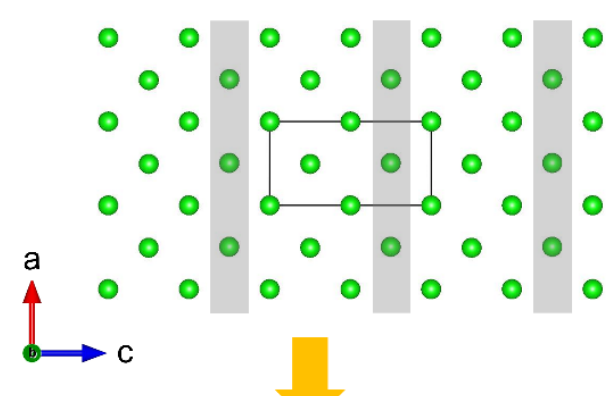

Li-layer
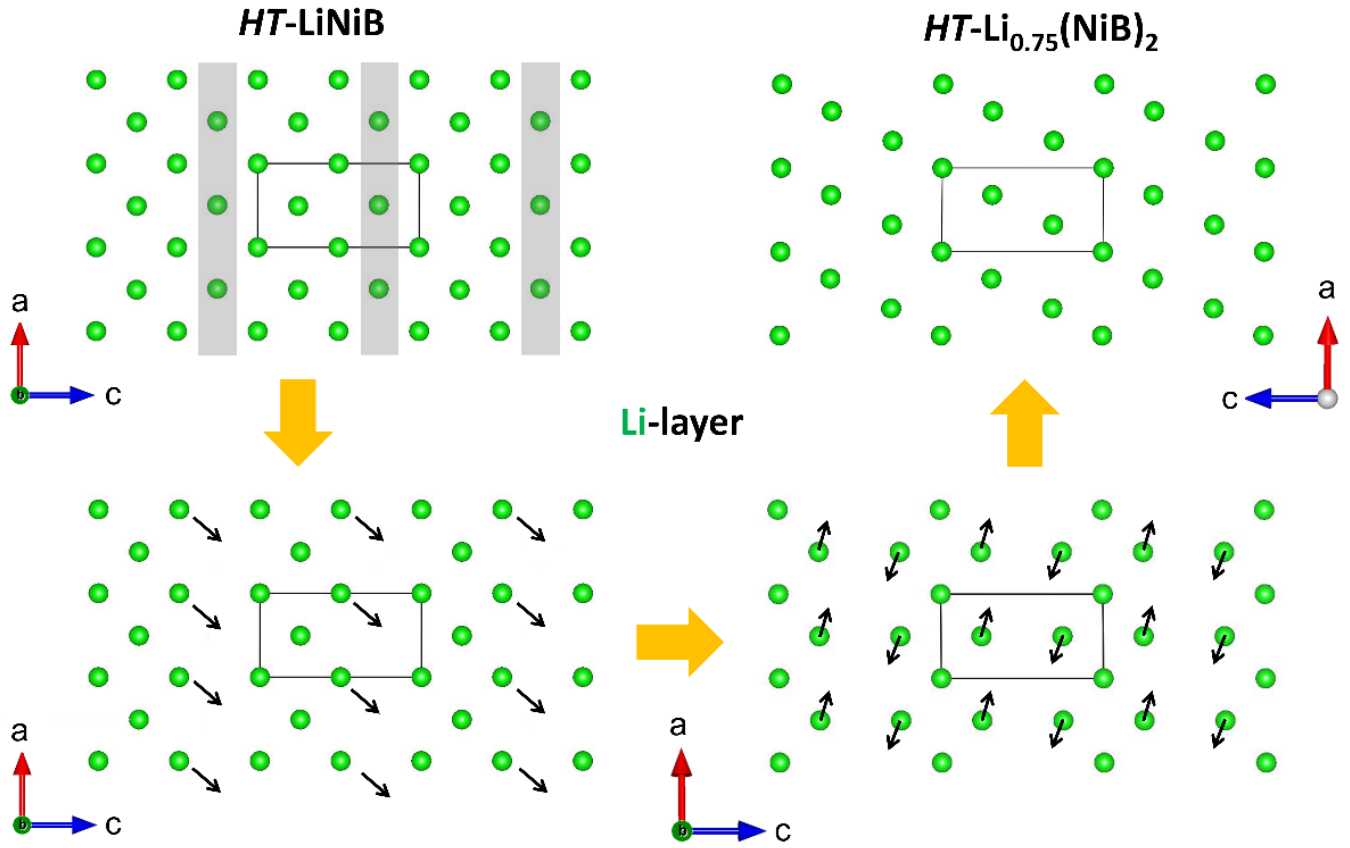

Figure S16. Proposed schematic of evolution of Li-layer from $H T$-LiNiB to $H T$-Li0.75(NiB)2.
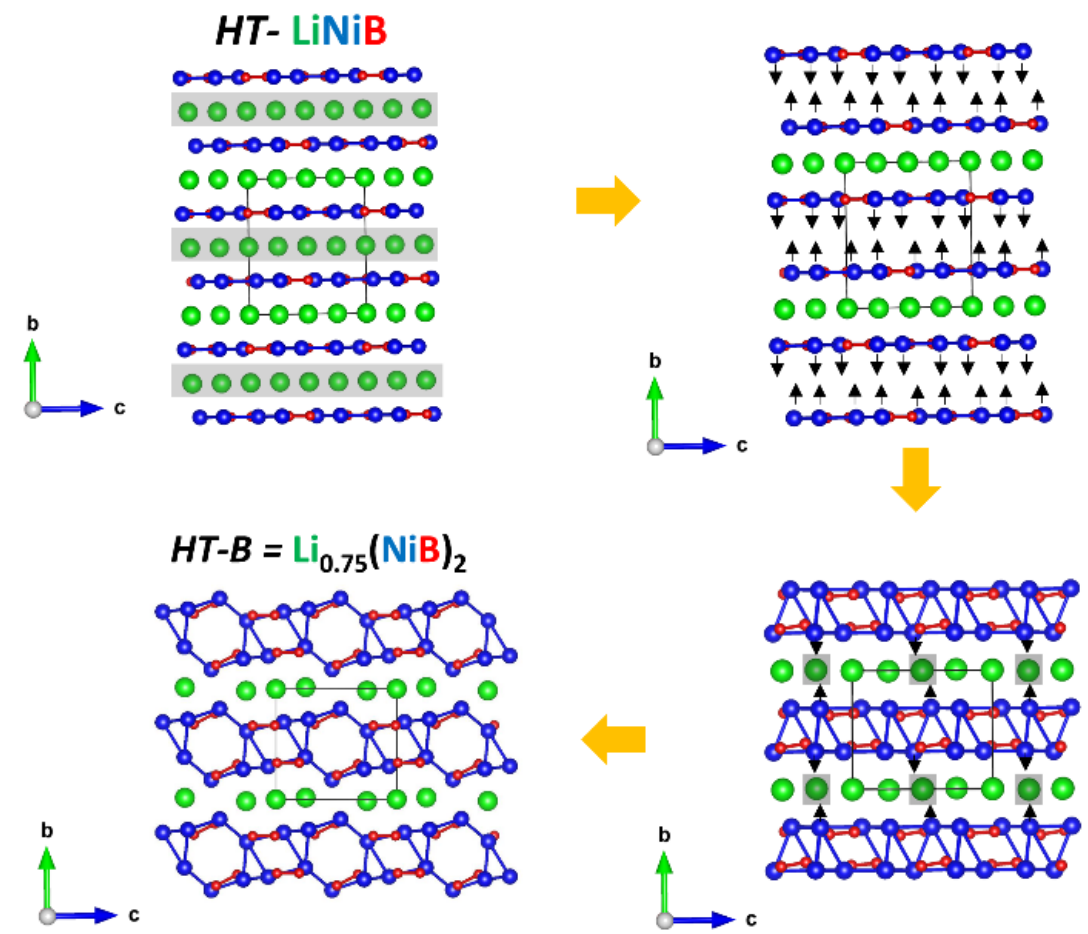

Figure S17. Proposed schematic of evolution of layers from $H T$-LiNiB to $H T$-Li0.75(NiB)2. 
Table S3. Atomic coordinates and isotropic equivalent displacement parameters of the $H T-B$ $\mathrm{Li} 0.75[\mathrm{NiB}]_{2}$ fragment. Refined parameters based on synchrotron powder X-ray PDF data at 295 $\mathrm{K}$ are listed.

\begin{tabular}{|c|c|c|c|c|c|}
\hline Site & Wyckoff site & $x$ & $y$ & $z$ & $U_{\text {iso, }} \AA^{2}$ \\
\hline \multicolumn{6}{|c|}{$\begin{array}{c}H T-B \operatorname{Li} 0.75[\mathrm{NiB}]_{2}(a P 20, P-1, a=3.94(1), b=6.92(1), c=7.57(2) \AA \\
\left.\alpha=89.9(6)^{\circ}, \beta=89.3(3)^{\circ}, \gamma=87.6(5)^{\circ}, Z=2, R=0.26\right)\end{array}$} \\
\hline Li1 & $1 a$ & 0 & 0 & 0 & $0.03(1)$ \\
\hline $\mathrm{Li} 2$ & $2 i$ & 0.423010 & 0.016070 & 0.246110 & $0.03(1)$ \\
\hline $\mathrm{Ni1}$ & $2 i$ & $0.47(1)$ & $0.701(6)$ & $0.064(4)$ & $0.007(2)$ \\
\hline $\mathrm{Ni} 2$ & $2 i$ & $0.743(6)$ & $0.178(3)$ & $0.465(4)$ & $0.007(2)$ \\
\hline $\mathrm{Ni3}$ & $2 i$ & $0.041(7)$ & $0.274(6)$ & $0.729(3)$ & $0.007(2)$ \\
\hline $\mathrm{Ni4}$ & $2 i$ & $0.279(5)$ & $0.383(3)$ & $0.242(4)$ & $0.007(2)$ \\
\hline B1 & $2 i$ & 0.245380 & 0.219180 & 0.504680 & $0.03(1)$ \\
\hline B2 & $2 i$ & 0.475310 & 0.681560 & 0.321030 & $0.03(1)$ \\
\hline B3 & $2 i$ & 0.031320 & 0.330640 & 0.008810 & $0.03(1)$ \\
\hline B4 & $2 i$ & 0.762520 & 0.331960 & 0.193100 & $0.03(1)$ \\
\hline
\end{tabular}
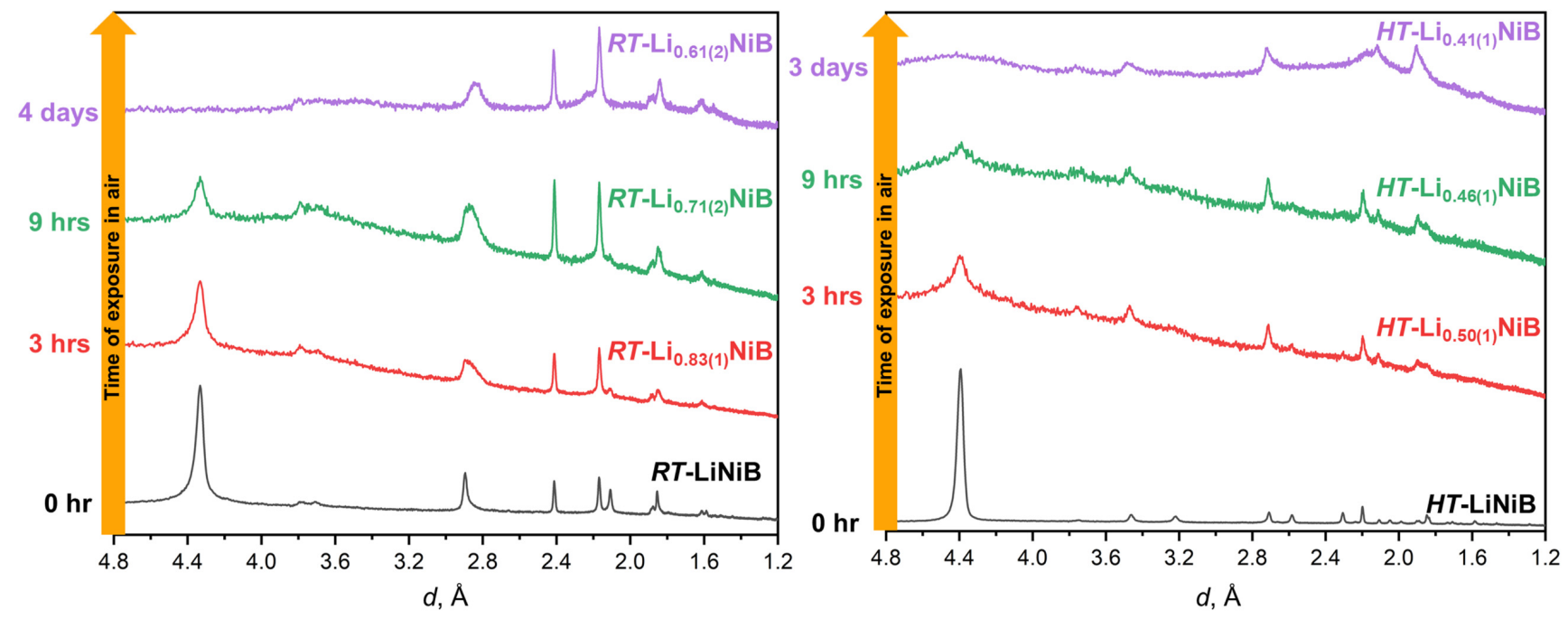

Figure S18. Powder X-ray diffraction (PXRD) patterns of $R T$-LiNiB and HT-LiNiB exposed to air for 3 hours and 9 hours. These samples were washed with DI water to remove $\mathrm{LiOH} \cdot \mathrm{H}_{2} \mathrm{O}$ impurity. The Li/Ni ratio was determined by ICP-MS data to confirm the gradual deintercalation of Li. PXRD patterns of samples exposed to air for 3 or 4 days are added for comparison. 
Table S4. Inter- and intralayer bond distances of $\mathrm{Ni}$ atoms in substructure $R T$-B. Intralayer bond distances are shaded.

\begin{tabular}{|c|c|c|c|c|c|}
\hline \multicolumn{6}{|c|}{$R T$-B } \\
\hline \multicolumn{3}{|c|}{ CN Nil } & \multicolumn{3}{|c|}{$\mathrm{CN} N \mathrm{Ni} 2$} \\
\hline \multirow{5}{*}{ Nil } & $\mathrm{Ni} 2$ & $2.52(1)$ & \multirow{5}{*}{$\mathrm{Ni} 2$} & Nil & $2.52(1)$ \\
\hline & $\mathrm{Ni} 2$ & $2.53(1)$ & & Nil & $2.53(1)$ \\
\hline & $\mathrm{Ni} 2$ & $2.44(1)$ & & Nil & $2.44(1)$ \\
\hline & Nil & $2.58(2)$ & & $\mathrm{Ni1}$ & $261(3)$ \\
\hline & $\mathrm{Ni} 2$ & $2.61(3)$ & & & $2.01(3)$ \\
\hline
\end{tabular}

Table S5. Inter- and intralayer bond distances of Ni atoms in substructure $H T$-B. Intralayer bond distances are shaded.

\begin{tabular}{|c|c|c|c|c|c|c|c|c|c|c|c|}
\hline \multicolumn{12}{|c|}{ HT-B } \\
\hline \multirow{4}{*}{ Nil } & $\mathrm{Ni3}$ & $2.51(5)$ & \multirow{4}{*}{$\mathrm{Ni} 2$} & \multirow{2}{*}{$\mathrm{Ni3}$} & \multirow{2}{*}{$2.44(4)$} & \multirow{4}{*}{$\mathrm{Ni3}$} & Nil & $2.54(5)$ & \multirow{4}{*}{$\mathrm{Ni4}$} & Ni1 & $2.57(5)$ \\
\hline & $\mathrm{Ni3}$ & $2.54(5)$ & & & & & $\mathrm{Ni} 2$ & $2.44(4)$ & & $\mathrm{Ni} 2$ & $2.84(4)$ \\
\hline & $\mathrm{Ni4}$ & $2.57(5)$ & & \multirow{2}{*}{$\mathrm{Ni4}$} & \multirow{2}{*}{$2.84(4)$} & & \multirow{2}{*}{ Ni4 } & \multirow{2}{*}{$2.65(5)$} & & $\mathrm{Ni4}$ & $2.71(5)$ \\
\hline & $\mathrm{Ni4}$ & $2.71(5)$ & & & & & & & & $\mathrm{Ni3}$ & $2.65(5)$ \\
\hline
\end{tabular}

Table S6. Averaged charge transfer in partially Li-deintercalated phases based on Bader analysis. Positive (negative) numbers indicate electron gain (loss). For RT-C and HT-C models, $\mathrm{Ni1}$ and $\mathrm{B} 1$ are the atoms in the layers adjacent to the Li layer, while $\mathrm{Ni} 2$ and $\mathrm{B} 2$ are at the layers without neighboring Li layer.

\begin{tabular}{|l|c|c|c|}
\hline & $\mathrm{Li}$ & $\mathrm{Ni}$ & $\mathrm{B}$ \\
\hline$R T(m)-\mathrm{LiNiB}\left(P 2_{1} / c\right)^{\mathrm{S} 1}$ & -0.843 & +0.322 & +0.521 \\
\hline$R T-B\left(\mathrm{Li}[\mathrm{NiB}]_{2}\right)$ & -0.826 & +0.156 & +0.257 \\
\hline$R T-\mathrm{C}\left(\mathrm{Li}[\mathrm{NiB}]_{3}\right)$ & -0.825 & $+0.103(\mathrm{Ni} 1)$ & $+0.310(\mathrm{~B} 1)$ \\
& & $-0.152(\mathrm{Ni} 2)$ & $+0.150(\mathrm{~B} 2)$ \\
\hline$H T-\mathrm{LiNiB}\left(P 2_{1} / m\right)^{\mathrm{S} 1}$ & -0.841 & +0.328 & +0.513 \\
\hline$H T-\mathrm{B} \mathrm{Li} 0.75[\mathrm{NiB}]_{2}$ & -0.802 & +0.024 & +0.277 \\
\hline$H T-B\left(\mathrm{Li}[\mathrm{NiB}]_{2}\right)$ & -0.821 & +0.158 & +0.253 \\
\hline$H T-\mathrm{C}\left(\mathrm{Li}[\mathrm{NiB}]_{3}\right)$ & -0.822 & $+0.154(\mathrm{Ni} 1)$ & $+0.268(\mathrm{~B} 1)$ \\
& & $-0.129(\mathrm{Ni} 2)$ & $+0.106(\mathrm{~B} 2)$ \\
\hline
\end{tabular}



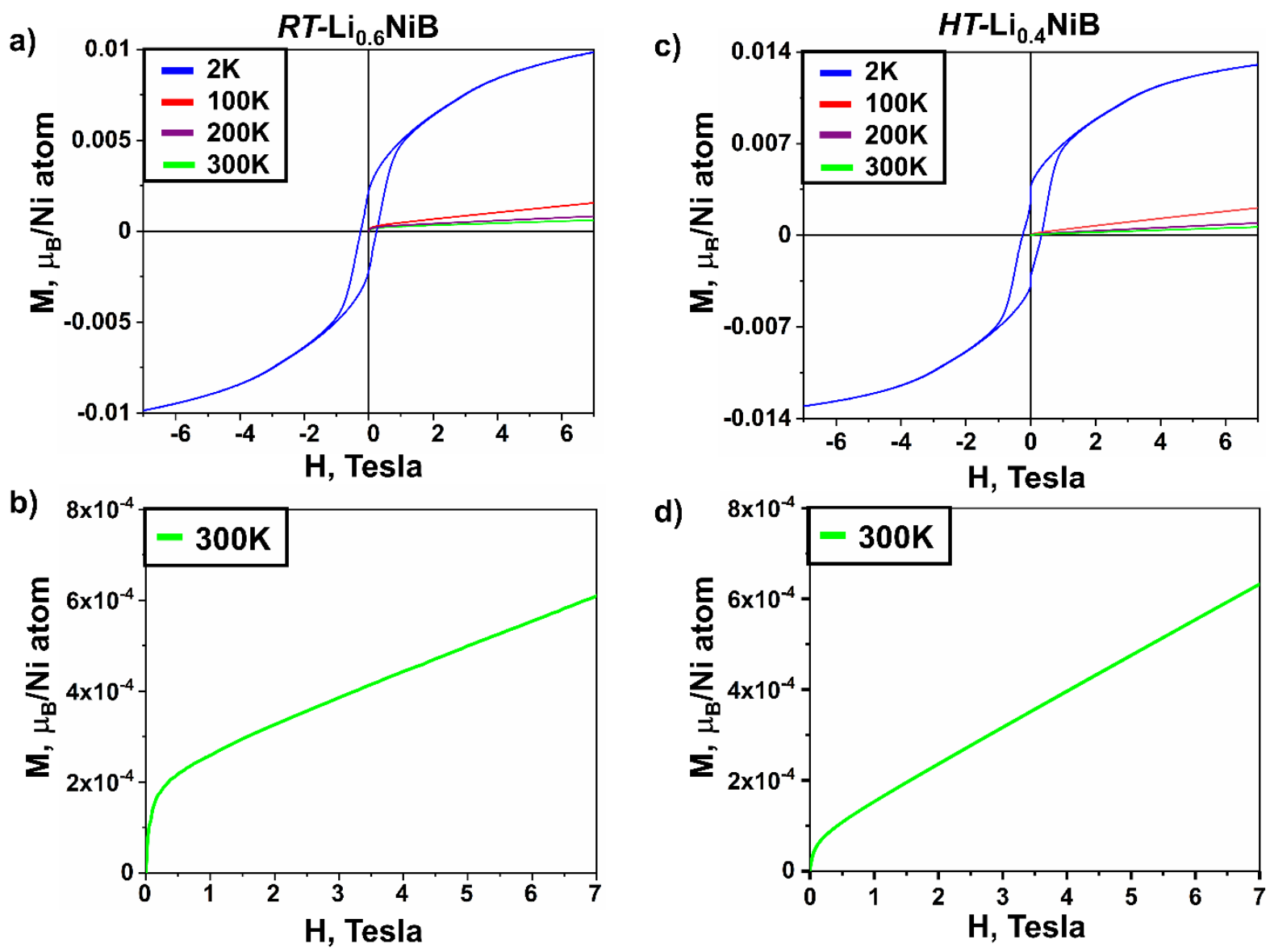

Figure S19. Field dependent magnetization at different temperatures $(2 \mathrm{~K}, 100 \mathrm{~K}, 200 \mathrm{~K}, 300$ $\mathrm{K})$ and at $300 \mathrm{~K}$ for polycrystalline samples of $R T-\operatorname{Li} 0.6 \mathrm{NiB}(a, b)$ and $H T-\mathrm{Li} 0.4 \mathrm{NiB}(c, d)$. The non-linear behavior of $M v s . H$ at $300 \mathrm{~K}$ is due to the contribution from traces of ferromagnetic impurity (estimated to be $\leq 0.02 \%$ ). 

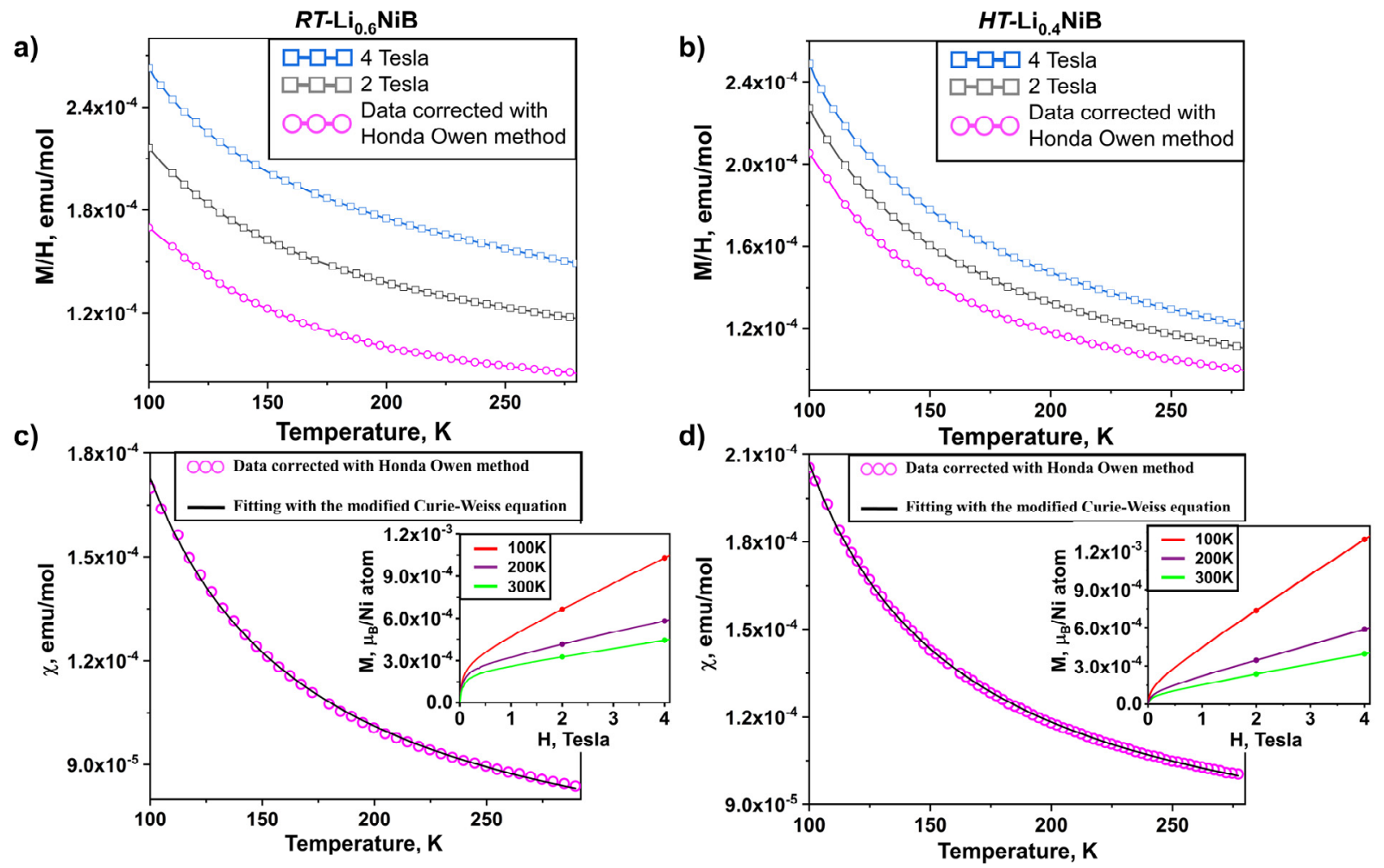

Figure S20. $M / H$ vs. $T$ plots at $2 \mathrm{~T}$ and $4 \mathrm{~T}$ for $(a) R T$-Li $0.6 \mathrm{NiB}$ and $(b) H T$-Li $0.4 \mathrm{NiB}$. Intrinsic susceptibilities, $\chi$, for $(c) R T$-Li0.6 $\mathrm{NiB}$ and $(d) H T$-Li0.4NiB were calculated by Honda-Owen method $^{\mathrm{S} 16, \mathrm{~S} 17}$ to account for the contribution of a ferromagnetic impurity (estimated to be $\leq$ $0.03 \%$ ). The corrected data were then fitted with the modified Curie-Weiss equation (Table S7). Insets in (c) and (d) show $M v s$. $H$ plots in $0-4 \mathrm{~T}$ range for $100 \mathrm{~K}, 200 \mathrm{~K}$ and $300 \mathrm{~K}$, while dots represent the magnetic fields for which the $M / H$ vs $T$ data were corrected by the Honda Owen method.

Table S7. Parameters of the best fit of the corrected by Honda-Owen method magnetic susceptibility to the modified Curie-Weiss: $\chi=\chi_{0}+C /(T-\theta)$ in the temperature range of $100-$ $300 \mathrm{~K}$.

\begin{tabular}{|l|c|c|}
\hline & $R T$-Li0.6NiB & $H T-\mathrm{Li} 0.4 \mathrm{NiB}$ \\
\hline Temperature-independent contribution, $\chi 0, \mathrm{emu} \mathrm{mol}^{-1}$ & $4.83(7) \times 10^{-5}$ & $6.06(4) \times 10^{-5}$ \\
\hline Curie constant, $C$, emu K mol ${ }^{-1}$ & $9.2(2) \times 10^{-3}$ & $9.5(1) \times 10^{-3}$ \\
\hline Paramagnetic Curie-Wiess temperature, $\theta, \mathrm{K}$ & $26(1)$ & $35(1)$ \\
\hline Effective magnetic moment per Ni atom, $\mu_{\text {eff, } \mu_{B}}$ & $0.272(3)$ & $0.277(2)$ \\
\hline
\end{tabular}




\section{References}

[S1] Gvozdetskyi, V.; Bhaskar, G.; Batuk, M.; Zhao, X.; Wang, R.; Carnahan, S. L.; Hanrahan, M. P.; Ribeiro, R. A.; Canfield, P. C.; Rossini, A. J.; Wang, C. Z.; Ho, K. M.; Hadermann, J.; Zaikina, J. V. Computationally driven discovery of a family of layered LiNiB polymorphs. Angew. Chem. Int. Ed. 2019, 131, 16002-16009.

[S2] PDXL: Integrated X-ray powder diffraction software, Version 2.8.1.1. Rigaku, 2018.

[S3] Chupas, P. J.; Qiu, X.; Hanson, J. C.; Lee, P. L.; Grey, C. P.; Billinge, S. J. L. Rapidacquisition pair distribution function (RA-PDF) analysis. J. Appl. Cryst. 2003, 36, 1342-1347.

[S4] Chupas, P. J.; Chapman, K. W.; Lee, P. L. Applications of an amorphous silicon-based area detector for high-resolution, high-sensitivity and fast time-resolved pair distribution function measurements. J. Appl. Cryst. 2007, 40, 463-470.

[S5] Toby, B. H.; Madden, T. J.; Suchomel, M. R.; Baldwin, J. D.; Von Dreele, R. B. A scanning CCD detector for powder diffraction measurements. J. Appl. Cryst. 2013, 46, 1058-1063.

[S6] Toby, B. H.; Von Dreele, R. B. GSAS-II: the genesis of a modern open-source all purpose crystallography software package. J. Appl. Cryst. 2013, 46, 544-549.

[S7] Juhas, P.; Davis, T.; Farrow, C. L.; Billinge, S. J. L. PDFgetX3: a rapid and highly automatable program for processing powder diffraction data into total scattering pair distribution functions. J. Appl. Cryst. 2013, 46, 560-566.

[S8] Farrow, C. L.; Juhas, P.; Liu, J. W.; Bryndin, D.; Božin, E. S.; Bloch, J.; Proffen, Th.; Billinge, S. J. L. PDFfit2 and PDFgui: computer programs for studying nanostructure in crystals. J. Phys.: Condens. Matter. 2007, 19, 335219-335225.

[S9] Kresse, G.; Furthmuller, J. Efficiency of ab-initio total energy calculations for metals and semiconductors using a plane-wave basis set. Comput. Mater. Sci. 1996, 6, 15.

[S10] Kresse, G.; Furthmuller, J. Efficient iterative schemes for ab initio total-energy calculations using a plane-wave basis set. Phys. Rev. B. 1996, 54, 11169.

[S11] Perdew, J. P.; Burke, K.; Ernzerhof, M. Generalized Gradient Approximation Made Simple. Phys. Rev. Lett. 1996, 77, 3865.

[S12] Bloechl, P. E. Projector augmented-wave method. Phys. Rev. B. 1994, 50, 17953.

[S13] Monkhorst, H. J.; Pack, J. D. Special points for Brillouin-zone integrations. Phys. Rev. B. 1976, 13, 5188-5192. 
[S14] Wu, S. Q.; Ji, M.; Wang, C. Z.; Nguyen, M. C.; Zhao, X.; Umemoto, K.; Wentzcovitch, R. M.; Ho, K. M. An adaptive genetic algorithm for crystal structure prediction. J. Phys. Condens. Matter. 2014, 26, 035402.

[S15] Zhao, X.; Nguyen, M. C.; Zhang, W. Y.; Wang, C. Z.; Kramer, M. J.; Sellmyer, D. J.; Li, X. Z.; Zhang, F.; Ke, L. Q.; Antropov, V. P.; Ho, K. M. Exploring the Structural Complexity of Intermetallic Compounds by an Adaptive Genetic Algorithm. Phys. Rev. Lett. 2014, 112, 045502.

[S16] Honda, K. Die thermomagnetischen Eigenschaften der Elemente. Ann. Phys. 1910, 337, 1027-1063.

[S17] Owen, M. Magnetochemische Untersuchungen. Die thermomagnetischen Eigenschaften der Elemente. II. Ann. Phys. 1912, 342, 657-699. 